\title{
Revealing the pathogenic changes of PAH based on multiomics characteristics
}

\author{
Li Zhang ${ }^{1,2+}$, Shaokun Chen ${ }^{1,2+}$, Xixi Zeng ${ }^{1,2}$, Dacen Lin ${ }^{1,2}$, Yumei Li ${ }^{2,3}$, Longxin Gui ${ }^{2}$ and Mo-jun Lin 1,2* $^{*}$
}

\begin{abstract}
Background: Pulmonary artery hypertension (PAH), which is characterized by an increase in pulmonary circulation blood pressure, is a fatal disease, and its pathogenesis remains unclear.

Methods: In this study, RNA sequencing (RNA-seq), tandem mass tags (TMT) and reduced representation bisulfite sequencing (RRBS) were performed to detect the levels of mRNA, protein, and DNA methylation in pulmonary arteries (PAs), respectively. To screen the possible pathways and proteins related to PAH, pathway enrichment analysis and protein-protein interaction (PPI) network analysis were performed. For selected genes, differential expression levels were confirmed at both the transcriptional and translational levels by real-time PCR and Western blot analyses, respectively.
\end{abstract}

Results: A total of 362 differentially expressed genes (|Fold-change $>1.5$ and $p<0.05), 811$ differentially expressed proteins (|Fold-change| $>1.2$ and $p<0.05$ ) and 76,562 differentially methylated regions (1000 bp slide windows, 500 bp overlap, $p<0.05$, and |Fold-change $>1.2)$ were identified when the PAH group $(n=15)$ was compared with the control group $(n=15)$. Through an integrated analysis of the characteristics of the three omic analyses, a multiomics table was constructed. Additionally, pathway enrichment analysis showed that the differentially expressed proteins were significantly enriched in five Kyoto Encyclopedia of Genes and Genomes (KEGG) biological pathways and ten Gene Ontology (GO) terms for the PAH group compared with the control group. Moreover, protein-protein interaction (PPI) networks were constructed to identify hub genes. Finally, according to the genes identified in the PPI and the protein expression fold-change, nine key genes and their associated proteins were verified by real-time PCR and Western blot analyses, including Col4a1, Itga5, Col2a1, Gstt1, Gstm3, Thbd, Mgst2, Kng1 and Fgg.

Conclusions: This study conducted multiomic characteristic profiling to identify genes that contribute to the hypoxia-induced PAH model, identifying new avenues for basic PAH research.

Keywords: Pulmonary artery hypertension, Pulmonary arteries, Multiomics, Proteomic, Transcriptomic, DNA methylation

\section{Background}

Pulmonary arterial hypertension (PAH) is clinically defined as the elevation of mean pulmonary artery pressure $(\mathrm{mPAP})>25 \mathrm{mmHg}$ at rest [1]. It is pathologically characterized by the proliferation, migration, antiapoptosis, or phenotype switching of pulmonary arterial endothelial cells, pulmonary arterial smooth muscle

\footnotetext{
*Correspondence: linmojunfi@126.com

${ }^{\dagger} \mathrm{Li}$ Zhang and Shaokun Chen contributed equally to this work

${ }^{1}$ Department of Physiology \& Pathophysiology, Fujian Medical University,

Fuzhou, China

Full list of author information is available at the end of the article
}

cells, and fibroblasts. Despite recent achievements in the treatment of $\mathrm{PAH}$, most current therapies only improve the symptoms, rather than cure them. Thus, there is an urgent need to explore the genes, pathways or epigenetic factors that drive PAH to identify potential therapeutic targets.

A number of previous transcriptomic and proteomic studies have revealed the pathological mechanisms underlying pulmonary hypertension in different samples; most of the studies were performed in lung homogenate samples [2-7] and circulating cells (peripheral blood) $[14,15]$, although some studies have been performed in 
pulmonary arterial samples [8-11] and specific cell types (isolated primary cells) $[12,13]$. The studies examined multiple different species, including Homo sapiens, Rattus norvegicus and Mus musculus. However, previous studies were primarily based on single-omics analyses, especially transcriptome analyses, and rarely included epigenetic analyses. DNA methylation is one of the most stable epigenetic modifications and is traditionally regarded as the major mediator of epigenetic regulation. Recent studies have demonstrated the role of epigenetic modifications in the pathogenesis of PAH [16-18], suggesting that DNA methylation may be associated with the etiology of PAH. Although genome-wide analyses have contributed greatly to our understanding of the genetic basis of PAH, the deeper and more comprehensive mechanisms of PAH must still be explained.

Chronic hypoxia causes a decrease in blood oxygen saturation, leading to the persistent constriction of pulmonary arterioles and pathological changes in blood vessels. These changes are clinically relevant, as hypoxia is one of the most common inducers of PAH worldwide [19-21]. The expression of vascular-specific genes can be masked in lung homogenates because intrapulmonary arteries represent only a small percentage of total lung tissues [22]. Therefore, based on previous studies and considering the pros and cons of different materials, pulmonary arteries (PAs) were chosen for this experiment, with the aim of identifying vascular-specific genes.

In this study, we aimed to identify gene expression patterns, potential signaling pathways and the epigenetic characteristics of PAs in rats suffering from hypoxiainduced PAH. PAs were isolated from connective tissues and cleaned. RNA sequencing (RNA-seq), tandem mass tags (TMT) and reduced representation bisulfite sequencing (RRBS) were performed to screen for differentially expressed genes (DEGs), differentially expressed proteins (DEPs) and differentially methylated regions (DMRs), respectively. Then, for the first time, we combined the information from these three omics analyses to identify the pathogenic characteristics of hypoxicinduced PAH in PAs. The integrated analysis of these multiomics sequencing data contributed to a detailed understanding of the mechanisms underlying $\mathrm{PAH}$, which may play an important role in the development of new and more effective treatment targets and contribute to the development of new therapeutic drugs for PAH.

\section{Methods}

\section{PAH models and sample collection}

Experiments were performed on male Sprague-Dawley (SD) rats (200-250 g), supplied by the animal center of the Fujian Medical University. All procedures were approved by the Animal Care and Use Committee of
Fujian Medical University. Hypoxia-induced PAH was produced using an established method [23, 24]. Rats were placed in a hypoxic chamber and exposed to $10 \%$ $\mathrm{O}_{2}$ for 3 weeks. Meanwhile, the control group was placed in normoxic conditions for 3 weeks. Right ventricle systolic pressure (RVSP) was measured by accessing the right ventricle through the jugular vein using a polyethylene catheter connected to a pressure transducer (YPJ01; Chengyi, China). Pressure signals were displayed continuously on an RM6240 polygraph (Chengyi, China). The right ventricular mass index (RVMI) was calculated by determining the right ventricle/(left ventricle + ventricular septal) $[\mathrm{RV} /(\mathrm{LV}+\mathrm{S})]$ mass ratio.

Rats were injected with heparin and anesthetized with urethane. The lungs were removed and transferred to a petri dish filled with cold, oxygenated modified Krebs solution containing the following (in $\mathrm{mM}$ ): $118 \mathrm{NaCl}$, $4.7 \mathrm{KCl}, 1.2 \mathrm{MgSO}_{4}, 1.18 \mathrm{KH}_{2} \mathrm{PO}_{4}, 25 \mathrm{NaHCO}_{3}, 10$ glucose, and $2 \mathrm{CaCl}_{2}$. Under a dissecting microscope, PAs were isolated from connective tissue and cleaned. In this experiment, the PAs were taken from hypoxia-induced PAH rats $(n=15)$ and normoxia control rats $(n=15)$. However, due to the necessary sample sizes for the multiomics analysis, we pooled the PAs from five animals from the same group into one sample. Therefore, both the PAH group and the control group contained three pooled samples each. Meanwhile, lung tissues were collected for hematoxylin-eosin staining.

\section{Transcriptomic analysis RNA isolation, purification, and quantification}

Total RNA was extracted from rats PAs using TRIzol (Invitrogen, Carlsbad, CA, USA) following the manufacturer's instructions. The quantity and purity of total RNA were assessed using a Bioanalyzer 2100 and the RNA 6000 Nano LabChip Kit (Agilent, CA, USA), with an RNA integrity number $>7.0$.

\section{CDNA library construction and sequencing}

Poly(A) mRNA was isolated from total RNA with poly$T$ oligo-attached magnetic beads (Invitrogen, Waltham, US). Following purification, the mRNA was fragmented into small pieces using divalent cations and incubated with Fragmentation Buffer (Illumina) in a preheated tube for $5 \mathrm{~min}$ at $94{ }^{\circ} \mathrm{C}$. Then, the cleaved RNA fragments were reverse-transcribed to create cDNA, which was used to synthesize U-labeled second-stranded DNAs using E. coli DNA polymerase I, RNase H and dUTPs. An A-base was then added to the blunt ends of each strand, preparing them for ligation with the indexed adapters. Each adapter contained a T-base overhang to ligate the adapter with the A-tailed fragmented DNA. Single-or dual-index adapters were ligated with the fragments, and 
size selection was performed using AMPureXP beads. After the heat-labile uracil-DNA glycosylase enzyme treatment of the U-labeled second-stranded DNAs, the ligated products were amplified using PCR under the following conditions: initial denaturation at $95^{\circ} \mathrm{C}$ for $3 \mathrm{~min}$; 8 cycles of denaturation at $98{ }^{\circ} \mathrm{C}$ for $15 \mathrm{~s}$, annealing at $60{ }^{\circ} \mathrm{C}$ for $15 \mathrm{~s}$, and extension at $72{ }^{\circ} \mathrm{C}$ for $30 \mathrm{~s}$; and then a final extension at $72{ }^{\circ} \mathrm{C}$ for $5 \mathrm{~min}$ (in accordance with the protocol provided with the mRNA-Seq Sample Preparation Kit [Illumina, San Diego, USA]). The average insert size for the paired-end libraries was $300 \mathrm{bp}$ ( $\pm 50 \mathrm{bp}$ ). Finally, we performed 150 bp paired-end sequencing on an Illumina Hiseq 4000 (LC Bio, China), following the vendor's recommended protocol.

\section{Data analysis}

First, Cutadapt [25] and in-house Perl scripts were used to remove the reads that contained adapter contamination, low-quality bases and undetermined bases. Hisat software (version 2.0) was used to compare the sequencing data with the reference genome, and the transcript was assembled using the results of the alignments. After the final transcriptome was generated, StringTie (version 1.3.0) [26] and Ballgown [27] were used to estimate the expression levels of all transcripts. StringTie was used to analyze the expression levels of mRNAs by calculating the FPKM. The DEGs were determined to be those genes with $\mid$ Fold-change $\mid>1.5$ and $p<0.05$.

\section{Tandem mass tags analysis}

\section{Sample preparation, protein digestion and TMT labeling}

Pulmonary artery samples were ground into powder in liquid nitrogen and extracted with lysis buffer. Two milliliters of lysis buffer (7 M urea, 4\% SDS, $1 \times$ Protease Inhibitor Cocktail [Roche Ltd. Basel, Switzerland]) was added to each sample, followed by sonication on ice and centrifugation at $13,000 \mathrm{rpm}$ for $10 \mathrm{~min}$ at $4{ }^{\circ} \mathrm{C}$. The protein concentration of the supernatant was determined using the BCA protein assay, $100 \mu \mathrm{g}$ of protein per condition was transferred into new tubes, and the final volume was adjusted to $100 \mu \mathrm{l}$ with $100 \mathrm{mM}$ TEAB. To each sample, $5 \mu \mathrm{l}$ of $200 \mathrm{mM}$ DTT was added, and samples were incubated at $50{ }^{\circ} \mathrm{C}$ for $1 \mathrm{~h}$. Then, $5 \mu \mathrm{l}$ of $375 \mathrm{mM}$ iodoacetamide was added, and the samples were incubated for $30 \mathrm{~min}$ at room temperature, protected from light. For each sample, proteins were precipitated with ice-cold acetone and were then redissolved in $100 \mu \mathrm{l}$ of $100 \mathrm{mM}$ TEAB. Then, the proteins were digested with sequence-grade modified trypsin (Promega, Madison, WI), and the resultant peptide mixture was labeled using chemicals from the 10-plex TMT Reagent Kit (Thermo Scientific, USA). The labeled samples were combined and desalted using a C18 SPE column (Sep-Pak C18, Waters, Milford, MA).

\section{High $\mathrm{pH}$ reverse phase separation}

The peptide mixture was redissolved in buffer A (buffer A: $10 \mathrm{mM}$ ammonium formate in water, $\mathrm{pH}$ 10.0 , adjusted with ammonium hydroxide) and then fractionated by high $\mathrm{pH}$ separation using an Aquity UPLC system (Waters Corporation, Milford, MA) connected to a reverse phase column (BEH C18 column, $2.1 \mathrm{~mm} \times 150 \mathrm{~mm}, 1.7 \mu \mathrm{m}, 300 \AA$, Waters Corporation, Milford, MA). High $\mathrm{pH}$ separation was performed using a linear gradient, increasing from $0 \% \mathrm{~B}$ to $45 \% \mathrm{~B}$ in 35 min (B: $10 \mathrm{mM}$ ammonium formate in $90 \% \mathrm{ACN}, \mathrm{pH}$ 10.0 , adjusted with ammonium hydroxide). The column flow rate was maintained at $250 \mu \mathrm{l} / \mathrm{min}$, and the column temperature was maintained at $45{ }^{\circ} \mathrm{C}$. Twelve fractions were collected, and each fraction was dried in a vacuum concentrator for the next step.

\section{Low $\mathrm{pH}$ nano-HPLC-MS/MS analysis}

Each fraction was resuspended with $32 \mu \mathrm{l}$ of solvent $\mathrm{C}$ (C: water with $0.1 \%$ formic acid; D: ACN with $0.1 \%$ formic acid), separated by nano liquid chromatography (LC) and analyzed by online electrospray tandem mass spectrometry (MS/MS). The experiments were performed on an EASY-nLC 1000 system (Thermo Fisher Scientific, Waltham, MA), connected to an Orbitrap Fusion mass spectrometer (Thermo Fisher Scientific, San Jose, $\mathrm{CA}$ ), and equipped with an online nanoelectrospray ion source. For each sample, $4 \mu \mathrm{l}$ of peptide was loaded onto the trap column (Thermo Scientific Acclaim PepMap C18, $100 \mu \mathrm{m} \times 2 \mathrm{~cm}$ ), with a flow rate of $10 \mu \mathrm{l} / \mathrm{min}$ for $3 \mathrm{~min}$, and subsequently separated on the analytical column (Acclaim PepMap C18, $75 \mu \mathrm{m} \times 25 \mathrm{~cm}$ ), with a linear gradient from 5\% D to $30 \% \mathrm{D}$ over $95 \mathrm{~min}$. The column was re-equilibrated at initial conditions for $15 \mathrm{~min}$. The column flow rate was maintained at $300 \mathrm{nl} / \mathrm{min}$, and the column temperature was maintained at $45{ }^{\circ} \mathrm{C}$. An electrospray voltage of $2.0 \mathrm{kV}$ versus the inlet of the mass spectrometer was used. The Orbitrap Fusion mass spectrometer was operated in the data-dependent mode to switch automatically between mass spectrometry (MS) and MS/MS acquisition modes. Survey full-scan MS spectra $(\mathrm{m} / \mathrm{z} 400-1600)$ were acquired in Orbitrap with a mass resolution of 60,000 at $\mathrm{m} / \mathrm{z} 200$. The automatic gain control (AGC) target was set to 500,000, and the maximum injection time was $50 \mathrm{~ms}$. MS/MS acquisition was performed in Orbitrap with a $3 \mathrm{~s}$ cycle time and a resolution of 15,000 at $\mathrm{m} / \mathrm{z} 200$. The intensity threshold was 50,000 , and the maximum injection time was $150 \mathrm{~ms}$. The AGC target was set to 150,000 , and the isolation window was $2 \mathrm{~m} / \mathrm{z}$. Ions with charge states of $2+, 3+$ and $4+$ 
were sequentially fragmented by higher energy collisional dissociation, with a normalized collision energy of $37 \%$. In all cases, one microscan was recorded using dynamic exclusion of $30 \mathrm{~s}$. The MS/MS fixed first mass was set at 110.

\section{Database searching and quantitative data analysis}

Tandem mass spectra were extracted by Proteome Discoverer software (Thermo Fisher Scientific, version 1.4.0.288). Charge state deconvolution and deisotoping were not performed. All MS/MS samples were analyzed using Mascot (Matrix Science, London, UK; version 2.3). Mascot was configured to search the UniProt database (Taxonomy: Rattus norvegicus, 36,076 entries), assuming the digestion enzyme trypsin. For protein identification, mass tolerances of $0.05 \mathrm{Da}$ for intact peptide masses and 0.1 Da for fragmented masses were permitted, with an allowance for one missed cleavage upon trypsin digest. Several parameters in Mascot were configured for peptide searching, including Gln $\rightarrow$ pyro-Glu (N-term Q), oxidation $(\mathrm{M})$ and deamidated $(\mathrm{NQ})$, as potential variable modifications, and carbamidomethyl (C), TMT 10-plex (N-term) and TMT 10-plex (K), as fixed modifications. The percolator algorithm was used to maintain the peptide-level false discovery rate (FDR) [28] below $1 \%$. A protein containing at least one unique peptide was required for quantitation. The quantitative protein ratios were weighted and normalized by the median ratio in Mascot. Proteins with an absolute fold-change greater than 1.2 and a $p$-value less than 0.05 were considered to be significant DEPs.

\section{Bioinformatics and annotations}

To determine the biological and functional properties of all of the identified proteins, we employed the hypergeometric test to perform Gene Ontology (GO) enrichment analysis and Kyoto Encyclopedia of Genes and Genomes (KEGG) pathway enrichment analysis using the DAVID system (https://david.ncifcrf.gov/, version 6.8). The default parameters of the DAVID system were used for calculation and analysis. Finally, the statistical significance test FDR $<0.05$ was used as a threshold for identifying significantly enriched KEGG pathways and GO terms associated with DEPs.

\section{Reduced representation bisulfite sequencing DNA sample preparation}

Total DNA was extracted using the QIAamp Fast DNA Tissue Kit (Qiagen, Dusseldorf, Germany), following the manufacturer's instructions. DNA quantity was measured by reading A260/280 ratios using a spectrophotometer. When the A260/280 ratios were located in the 1.8 to 2.0 range, DNA was available.

\section{DNA fragmentation and bisulfite conversion}

The DNA samples were fragmented using sonication and were then subjected to bisulfite conversion with the EZ DNA Methylation-Gold ${ }^{\mathrm{TM}}$ Kit (Zymo Research, USA) following the manufacturer's instructions. Briefly, add $900 \mu \mathrm{l}$ water, $50 \mu \mathrm{l}$ of M-Dissolving Buffer and $300 \mu \mathrm{l}$ of M-Dilution Buffer to one tube of CT Conversion Reagent and mix for $10 \mathrm{~min}$ firstly. Secondly, add $130 \mu \mathrm{l}$ of the prepared CT Conversion Reagent to $20 \mu \mathrm{l}$ of DNA sample, performed the following temperature steps: $98^{\circ} \mathrm{C}$ for $10 \mathrm{~min}, 64^{\circ} \mathrm{C}$ for $2.5 \mathrm{~h}$, and then hold at $4{ }^{\circ} \mathrm{C}$. Thirdly, add $600 \mu \mathrm{l}$ of M-Binding Buffer to a Zymo-spin IC Column. After centrifuged at full speed, add $100 \mu \mathrm{l}$ of M-Wash Buffer to the column, spin $30 \mathrm{~s}$. Fourthly, add $200 \mu \mathrm{l}$ of M-Desulphonation Buffer to the column and wait for $20 \mathrm{~min}$ and spin at full speed for $30 \mathrm{~s}$. And then, add $200 \mu \mathrm{l}$ of M-Wash Buffer to the column, spin $30 \mathrm{~s}$, repeat this wash step one more time. Finally, add $10 \mu \mathrm{l}$ of M-Elution Buffer directly to the column matrix, place into a $1.5 \mathrm{ml}$ tube and spin briefly to elute the DNA. According to the steps of this kit, the transformed products were obtained and applied to the ssDNA quantification of nanodrop, and the cycle number of library amplification was determined. Bisulfite-treated ssDNA fragments were used for library construction.

\section{Library construction and sequencing}

The Accel-NGS Methyl-Seq DNA Library Kit (Swift, MI, USA) was utilized to attach adapters to single-stranded DNA fragments. Briefly, as in the protocol shown below, the adaptase step was a highly efficient, proprietary reaction that simultaneously performed end repair, the tailing of $3^{\prime}$ ends, and the ligation of the first truncated adapter complement with $3^{\prime}$ ends. The extension step was used to incorporate a truncated adapter 1 via a primer extension reaction. The ligation step was used to add the second truncated adapter to the bottom strand only. The indexing PCR step increased the yield and incorporated full-length adapters. Bead-based solid phase reversible immobilization clean-ups were used to remove both oligo nucleotides and small fragments, as well as to change the enzymatic buffer composition. Finally, we performed pair-end $2 \times 150$ bp sequencing on an Illumina Hiseq 4000 platform housed in the LC Sciences.

\section{Bioinformatics analysis}

First, Cutadapt and in-house Perl scripts were used to remove reads that contained adapter contamination, lowquality bases and undetermined bases. Then, sequence quality was verified using FASTQC (http://www.bioin formatics.babraham.ac.uk/projects/fastqc/, version 0.10.1). Reads that passed quality control were mapped to the reference genome using WALT [29]. After alignment, reads 
were further deduplicated using SAM tools [30]. For each cytosine (or guanine corresponding to a cytosine on the opposite strand) in the reference genome sequence, the DNA methylation level was determined as the ratio of the number of reads supporting $C$ (methylated) to the number of total reads (methylated and unmethylated) using in-house Perl scripts and MethPipe [31]. DMRs were calculated using the $\mathrm{R}$ package-Methyl Kit [32] with default parameters (1000 bp slide windows, 500 bp overlap, $p$-value $<0.05)$ and $\mid$ Fold-change $\mid>1.2$.

\section{Integrated analysis of the multiomics results}

There is a translational relationship between mRNA and protein. Protein, as the translation product of mRNA, performs specific functions. The UniProt database (https ://www.uniprot.org/) was used to obtain relationships between mRNAs and proteins to establish an association database. In addition, by integrating DNA methylation data, the mRNA data was annotated with methylated region information. Thus, a table containing three types of omics information was constructed. The tool we used for this integrative analysis was ACGT101-COR (Version 1.1). ACGT101-COR is an in-house pipeline script (LC Sciences, Houston, TX, USA).

\section{Protein-protein interaction (PPI) networks}

Protein-protein interaction information for the DEPs in each selected KEGG pathways $(\mathrm{FDR}<0.05)$ was acquired using the Search Tool for the Retrieval of Interacting Genes (STRING) database (http://www.stringdb.org/). Then, Cytoscape software (version 3.5.1) was used to construct the PPI networks. PPI networks could help us to identify the key genes involved in PAH development, based on interaction relationships.

\section{Real-time PCR analysis}

Total RNA was extracted from PAs using TRIzol. cDNA was synthesized with the Transcriptor First Strand cDNA Synthesis Kit (Roche, Basel, Switzerland), using random oligo (dT) primers. To determine the expression levels of key genes, real-time PCR experiments were performed using the Fast Start DNA Master SYBR Green I Kit and Light Cycler 2.0 (Roche, Basel, Switzerland). Serially diluted solutions of $\beta$-actin cDNA-containing plasmids with known copy numbers were used during each PCR experiment to create a linear regression for the analysis of the $\beta$-actin standard. All expression levels were normalized to the levels of internal $\beta$-actin.

\section{Western blot analysis}

Protein samples were separated on standard 12\% SDSpolyacrylamide gels and transferred to a PVDF membrane. After blocking with 5\% skim milk in PBS for $2 \mathrm{~h}$, membranes were incubated with antibodies against the proteins, including Col4a1, Itga5, Col2a1, Gstt1, Gstm3 and $\beta$-actin, purchased from BOSTER (Wuhan, China), and Thbd, purchased from BIOSS (Beijing, China), overnight at $4{ }^{\circ} \mathrm{C}$, followed by incubation with secondary antibodies, diluted with secondary antibody dilution buffer, at room temperature for $2 \mathrm{~h}$. Immunoreactive bands were detected using enhanced chemiluminescence (ECL) reagent (Thermo, Carlsbad, CA, USA) to visualize the bands, and the optical density of each blot was normalized to that of $\beta$-actin and presented as the relative optical density.

\section{Statistical analysis}

Statistical analysis was performed in GraphPad Prism 5 (GraphPad Software Inc., La Jolla, CA) software. Mean responses by group were compared by Student $t$-tests. Comparisons with $p$ values less than 0.05 are indicated by asterisks in the diagrams ( $p$ values less than 0.01 are indicated by two asterisks).

\section{Results \\ Verification of hypoxia-induced PAH models}

Hypoxic rat models were established and confirmed in this study. RVSP was significant increased from $21.03 \pm 0.6966 \mathrm{mmHg}$ (control) to $45.97 \pm 1.842 \mathrm{mmHg}$ in the hypoxia-induced rats (Fig. 1a, b). RVMI was approximately $50 \%$ higher in hypoxic rats $(40.84 \pm 1.667 \%)$ than in normoxic controls $(26.47 \pm 0.9474 \%)$ (Fig. 1c). Hematoxylin and eosin staining showed that the PAs were thickened, and remodeling was pronounced in hypoxic rats compared with normoxic controls (Fig. 1d). These results indicated that the generation of hypoxia-induced PAH rat model was successful.

\section{Screening the differential characteristics in PAH}

The PA samples from PAH and normal rats were subjected to high-throughput sequencing, including RNAseq, TMT and RRBS to identify gene expression, protein expression and epigenetic changes, respectively. The quality control of processed RNA-seq data was performed and shown in Additional file 1: Table S1. DEGs between the hypoxic and control groups were identified by the R-package Ballgown. After filtering $(>1.5$ fold change, $p<0.05), 362$ genes were detected as being significantly differentially expressed (168 up- and 194 downregulated) in the hypoxic group compared with the control group (Fig. 2a). As shown in Fig. 2b, a heatmap of the significantly dysregulated genes depicts a clustered gene expression pattern between the hypoxic and control groups. Volcano plots showed significant differences (as negative $\log p$ values) in the differential expression means between the PAH and controls (Fig. 2c). Because proteins 

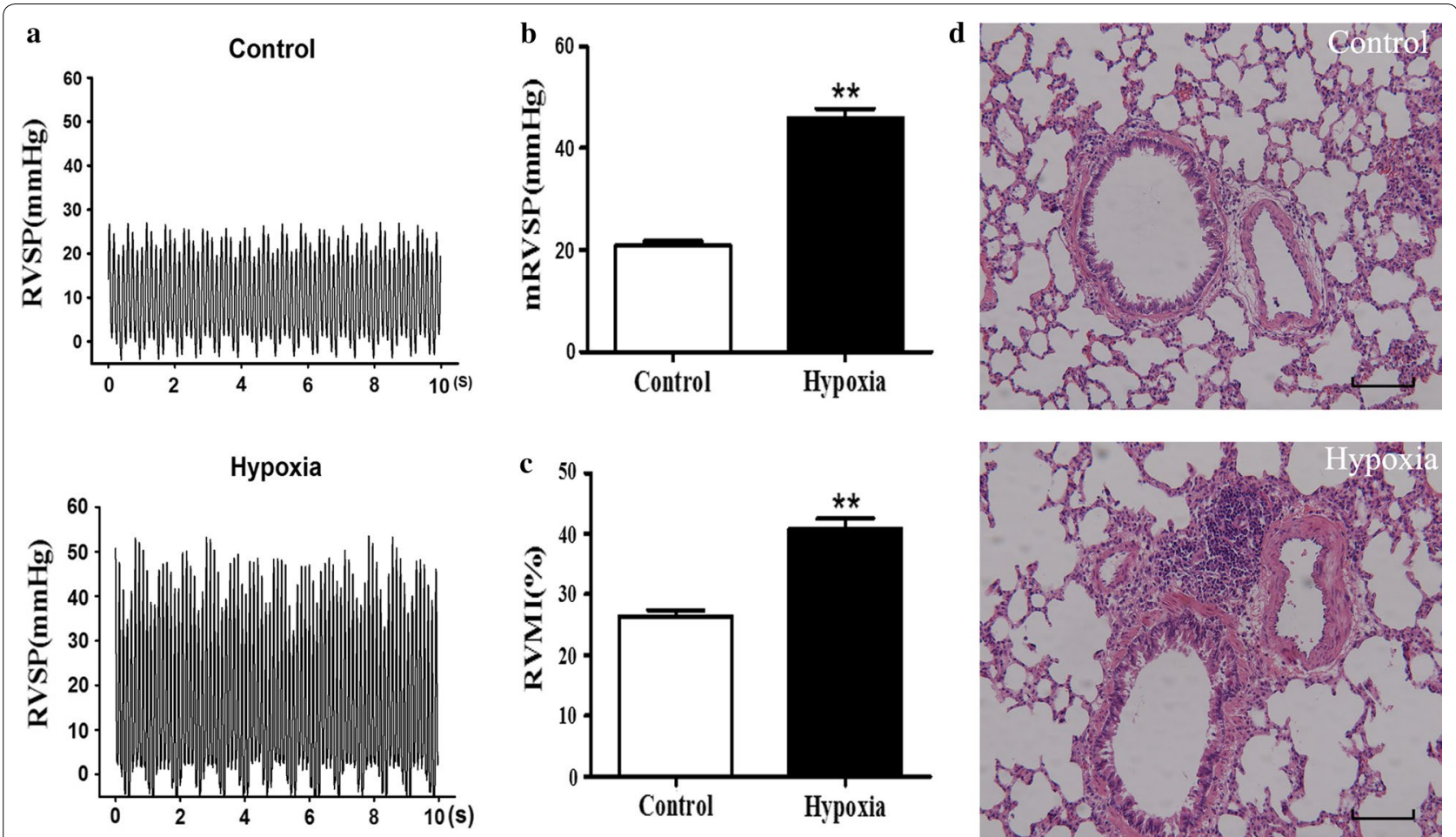

Fig. 1 Validation of pulmonary artery hypertension in hypoxia-treated rats. a, b Representative right ventricular pressure (RVSP) recorded from control and hypoxic rats. c Right ventricular mass index (RVMI) showed right ventricular hypertrophy, as indexed by the right ventricle/(left ventricle + ventricular septal) $[\mathrm{RV} /(\mathrm{LV}+\mathrm{S})]$ mass ratio. $\mathbf{d}$ Comparison of the PAs from the hypoxic group and with those from the normoxic control group, as assessed by the hematoxylin-eosin staining of paraffin sections

represent the actual functional molecules, TMT was conducted to investigate the differences in proteomic levels between the two groups. After data filtering (>1.2-fold change, $p<0.05), 811$ differentially expressed proteins (356 up- and 455 downregulated) were observed (Fig. 2d). Volcano plots show the differential expression of proteins in Fig. 2e. Meanwhile, the R package-methyl Kit was used to analyze the DMRs with the standard screening criteria (1000 bp windows, 500 bp overlap, $p<0.05$ and $>1.2$ fold change). Figure $2 \mathrm{f}$ shows that a total of 76,562 DMRs were identified among promoter (1678 hyper- and 1452 hypomethylated regions), exon (2276 hyper- and 2084 hypomethylated regions), intron (1706 hyper- and 1582 hypomethylated regions) and intergenic (37,250 hyperand 28,534 hypomethylated regions) areas. Overall, different characteristics between the two groups could be observed through multiomics sequencing.

\section{Integrated analysis of multiomics characteristics}

Based on the information regarding the 811 DEPs, 362 DEGs and 76,562 DMRs, the UniProt database was used to integrate and establish a correlation relationship among the multiple omics analyses. A total of 3991 genes were correlated among the three types of omics information, with $p$ values for the difference between $\mathrm{PAH}$ and control groups being less than 0.05 for at least one of the omics analyses (the integrated omics analysis ensured that changes in DNA methylation met the standard of fold change $>1.2$ and $p<0.05$ ). After sorting the fold-changes in protein expression, 10 of the top up- and downregulated proteins in the PAH group are displayed in Table 1. And three omics correlation table was shown in the Additional file 2: Table S2. Taken together, these findings constitute a multiomics library for further study in $\mathrm{PAH}$.

\footnotetext{
(See figure on next page.)

Fig. 2 Different characteristics between the hypoxic group and the control group. a The pie chart shows the DEGs. b Gene expression heatmap of hypoxia versus control groups: unsupervised hierarchical clustering analysis of the significantly dysregulated genes. Red: upregulated genes; green: downregulated genes. c Volcano plots for the transcriptome comparisons between the hypoxic group and the control group (Fold change > 1.5 and $p<0.05)$. $\mathbf{d}$ The pie chart shows the DEPs. e Volcano plots for the proteome comparisons between the hypoxic group and the control group (Fold change $>1.25$ and $p<0.05$ ). f The pie chart shows the DMRs, including promoter, exon, intron, and intergenic regions. The pie chart shows the number and proportion of upregulated and downregulated
} 
a

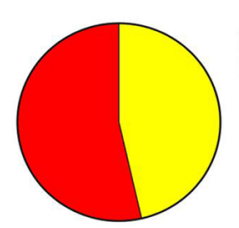

$53.59 \%$ (168) down-regulation

$\square 46.41 \%$ (194) up-regulation

DEGs_Total $=362$

c

CHvscon

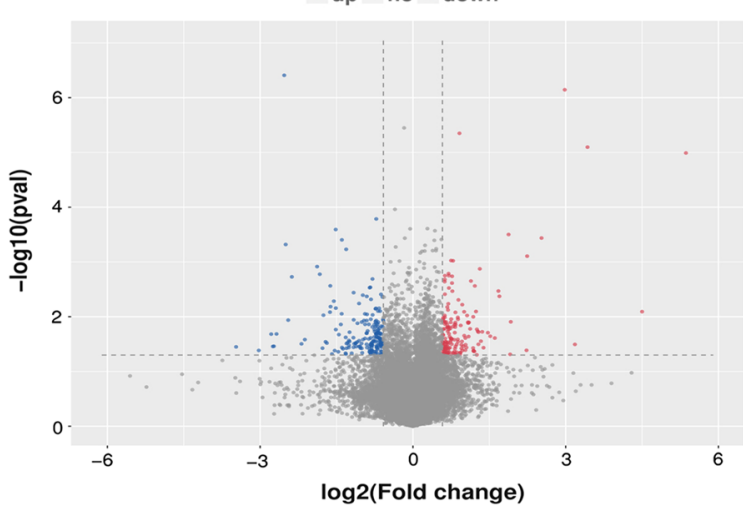

e CH_Vs_con

CH_Vs_Con no - down

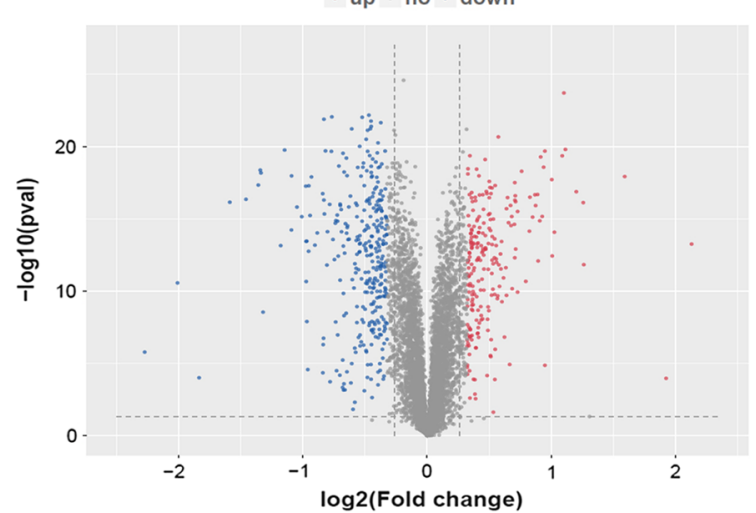

b

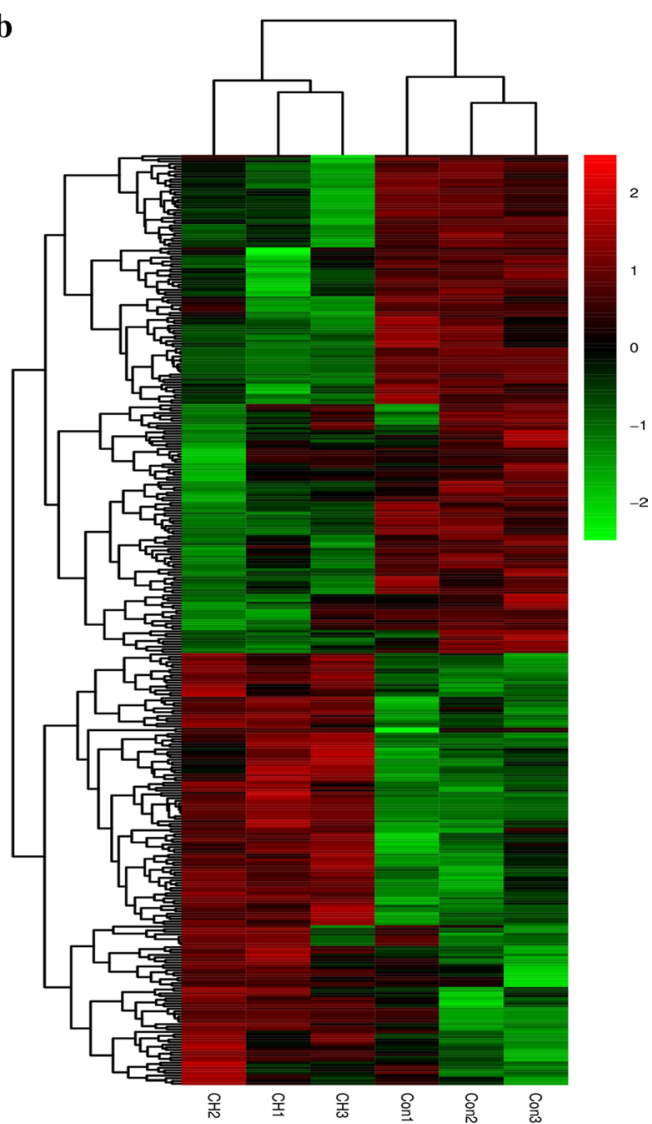

d

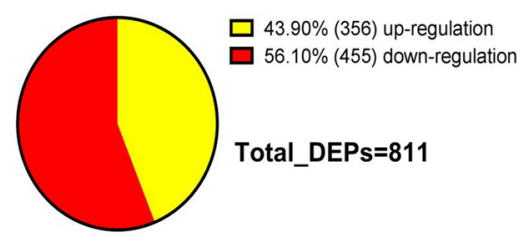

f

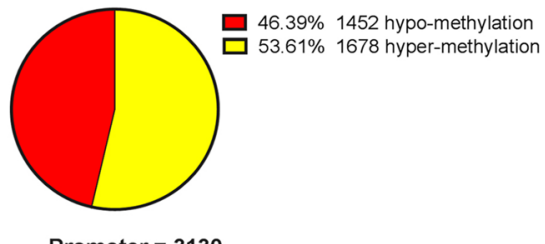

Promoter $=\mathbf{3 1 3 0}$

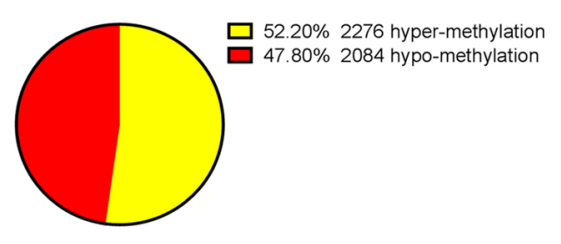

Exon $=4360$
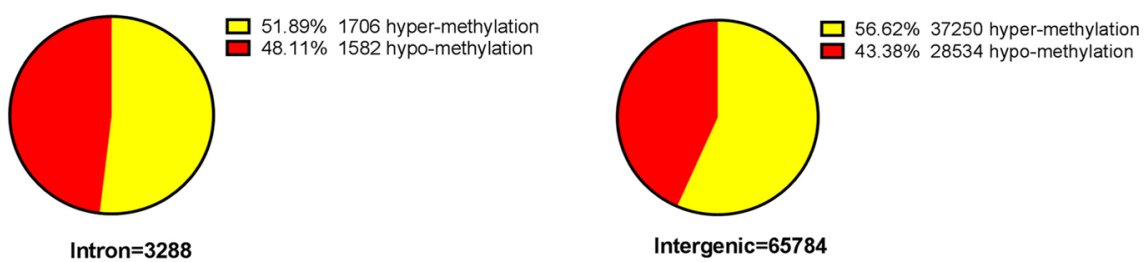


\section{Dysregulated biological functions in PAH}

To further identify the novel biological pathways associated with PAH, KEGG and GO analysis were applied. Based on the selected 811 DEPs, 17 KEGG pathways were selected using $p<0.05$ as the standard (Fig. 3a). Based on a 5\% FDR, the 7 KEGG pathways with the lowest $p$ values were screened for further analyses, including complement and coagulation cascades ( $r n o 04610, p=1.78 \mathrm{E}-13$, $\mathrm{FDR}=2.25 \mathrm{E}-10$ ), drug metabolism-cytochrome $\mathrm{P} 450$ (rno00982, $\quad p=2.38 \mathrm{E}-07, \quad \mathrm{FDR}=0.0003)$, metabolism of xenobiotics by cytochrome P450 (rno00980, $p=1.18 \mathrm{E}-05, \quad \mathrm{FDR}=0.015), \quad$ extracellular matrix (ECM)-receptor interaction (rno04512, $p=1.79 \mathrm{E}-05$, $\mathrm{FDR}=0.0227$ ), focal adhesion (rno04510, $p=3.18 \mathrm{E}-05$, $\mathrm{FDR}=0.0403$ ), chemical carcinogenesis (rno05204, $p=3.72 \mathrm{E}-06, \mathrm{FDR}=0.0047)$ and systemic lupus erythematosus (rno05322, $p=0.0000371824599510135$, $\mathrm{FDR}=0.047$ ). The chemical carcinogenesis and systemic lupus erythematosus pathways were not included in subsequent analyses, as they are associated with specific human disease pathways. Similarly, GO pathway enrichment analysis was conducted to identify the functional damage terms, and 90 terms were identified using the filter $p<0.05$ (shown in Additional file 3: Table S3). By raising the screen standard to $p<0.01,56$ terms were identified (Fig. 3b). Among these, the top ten terms had FDR $<0.05$. The three ontology nodes with the lowest $p$ values were sarcoplasmic reticulum (cellular component, GO: $0016529, p=3.67 \mathrm{E}-09, \quad \mathrm{FDR}=5.04 \mathrm{E}-06)$, basement membrane (cellular component, GO: 0005604, $p=3.08 \mathrm{E}-08, \mathrm{FDR}=0.00004)$ and negative regulation of endopeptidase activity (biologic process, GO: 0010951, $p=8.83 \mathrm{E}-08, \mathrm{FDR}=0.00015)$. Furthermore, rich factors showed the ratio of the number of DEPs to the number of total proteins in each pathway identified by the KEGG and GO analyses (Fig. 3c, d). More importantly, heatmap analysis was performed for the significant KEGG pathways to show the DEG and DEP information for each pathway. The methylated or unmethylated genes are marked in Fig. 4. This analysis allows the visualization of the multiomics information for the selected key KEGG pathways. Meanwhile, the detailed multiomics information of Fig. 4 is shown in Additional file 4: Table S4.

\section{PPI network identification of hub node genes}

As shown in Fig. 5, the genes of the five KEGG pathways identified above were used to construct protein-protein interaction networks using the STRING database, respectively. The genes with more joint-edges have more important biological functions [33]. Therefore, genes those have more interaction relationships with other genes may play important roles in the process of PAH. In our study, the degree of the genes, which is the number of joint-edges, was calculated for each selected KEGG pathways (Table 2). Then, the hub genes were labeled yellow in the Fig. 5, which had higher degrees were selected for further verification.

\section{Verification of the key genes}

According to the degree of the genes in the PPI and the expression fold-change of their associated proteins, nine key genes were verified by real-time PCR analyses. Mgst2, Kng1, Fgg, Col4a1 and Col2a1 were upregulated, whereas Itga5, Gstt1, Gstm3 and Thbd were downregulated in PAs from the PAH group compared with those from the control group. The mRNA levels of these genes tended to be consistent with the sequencing results, except for Col2a1. Itga5, Gstm3, Thbd and Gstt1 were significantly downregulated $(p<0.01)$, and Kng1 was significantly upregulated $(p<0.01)$ in PAs from the PAH group compared with those from the control group (Fig. 6a). Then, we performed Western blot analyses of these genes to identify protein level changes. As expected, the protein expression levels were consistent with the sequencing results. Fgg and Col4a1 were significantly upregulated, while Itga5, Gstt1, Gstm3, Col2a1 and Thbd were significantly downregulated in PAs from the PAH group compared with those from the control group (all $p<0.01$ ) (Fig. 6b). Together, verification using real-time PCR and Western blot further indicated that the sequencing results were reliable.

\section{Discussion}

In this study, we identified novel dysregulated genes and pathways in hypoxia-induced PAH. Using high-throughput sequencing and the integrated analysis of the mRNA expression, protein expression and DNA methylation data, we established DNA methylation, mRNA and protein profiles of the same samples to investigate the complexity of gene dysregulation in PAH. To date and to the best of our knowledge, only three studies have previously investigated compartment-specific gene expression patterns in the PAs from PAH models using high-throughput screening $[8,10,11]$. In our study, PAs were used for the experiments. RNA-seq, TMT and RRBS were combined to screen the different characteristics of the PAH group compared with the control group. This is the first study to integrate multiomics characteristics to create PA profiles for hypoxia-induced PAH models.

In our study, seven KEGG pathways and ten GO terms were selected by KEGG pathway enrichment and GO enrichment analyses, respectively. Complement and coagulation cascades was the top significantly regulated KEGG pathway identified in the PAH group. A previous study exploited an iTRAQ-based proteomic method to 


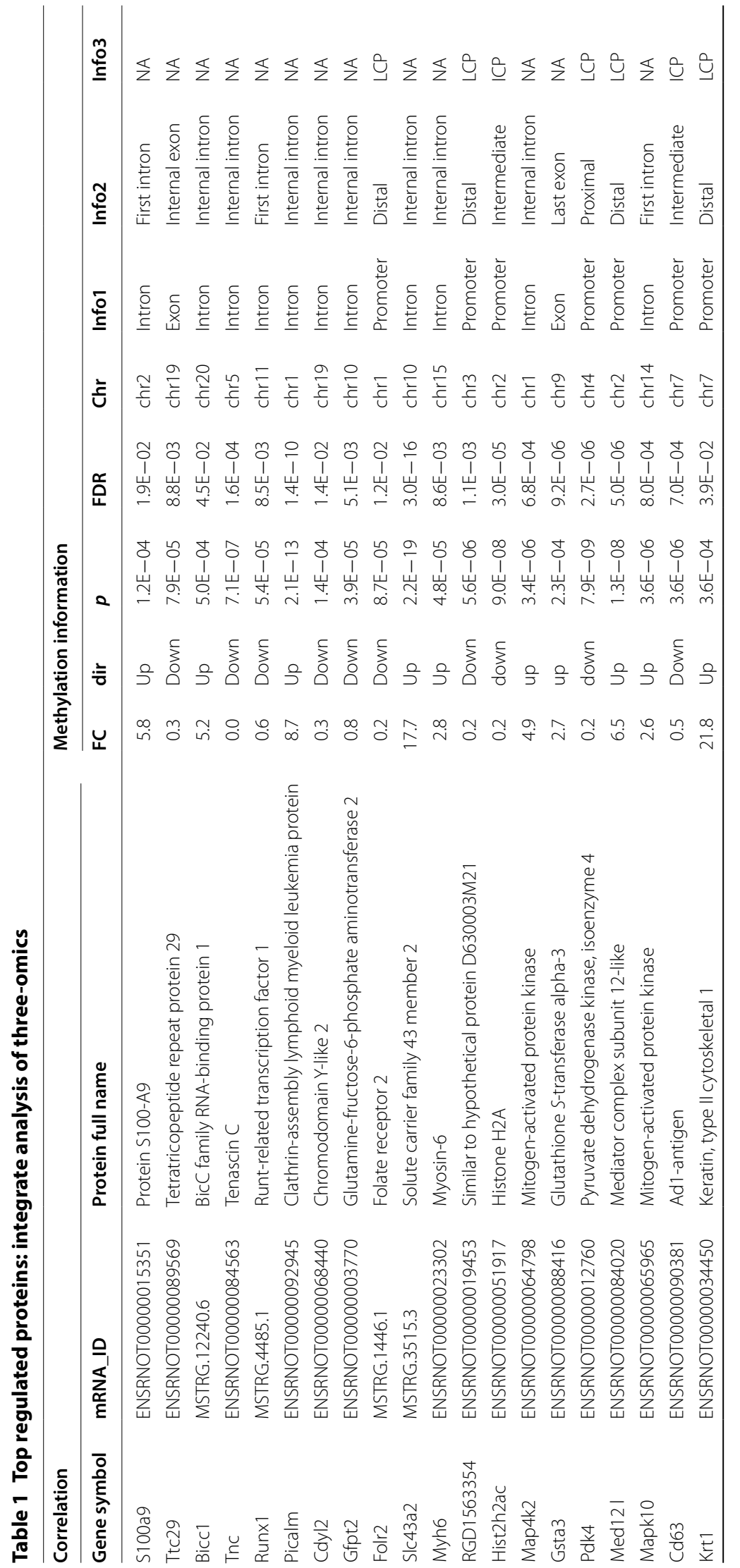




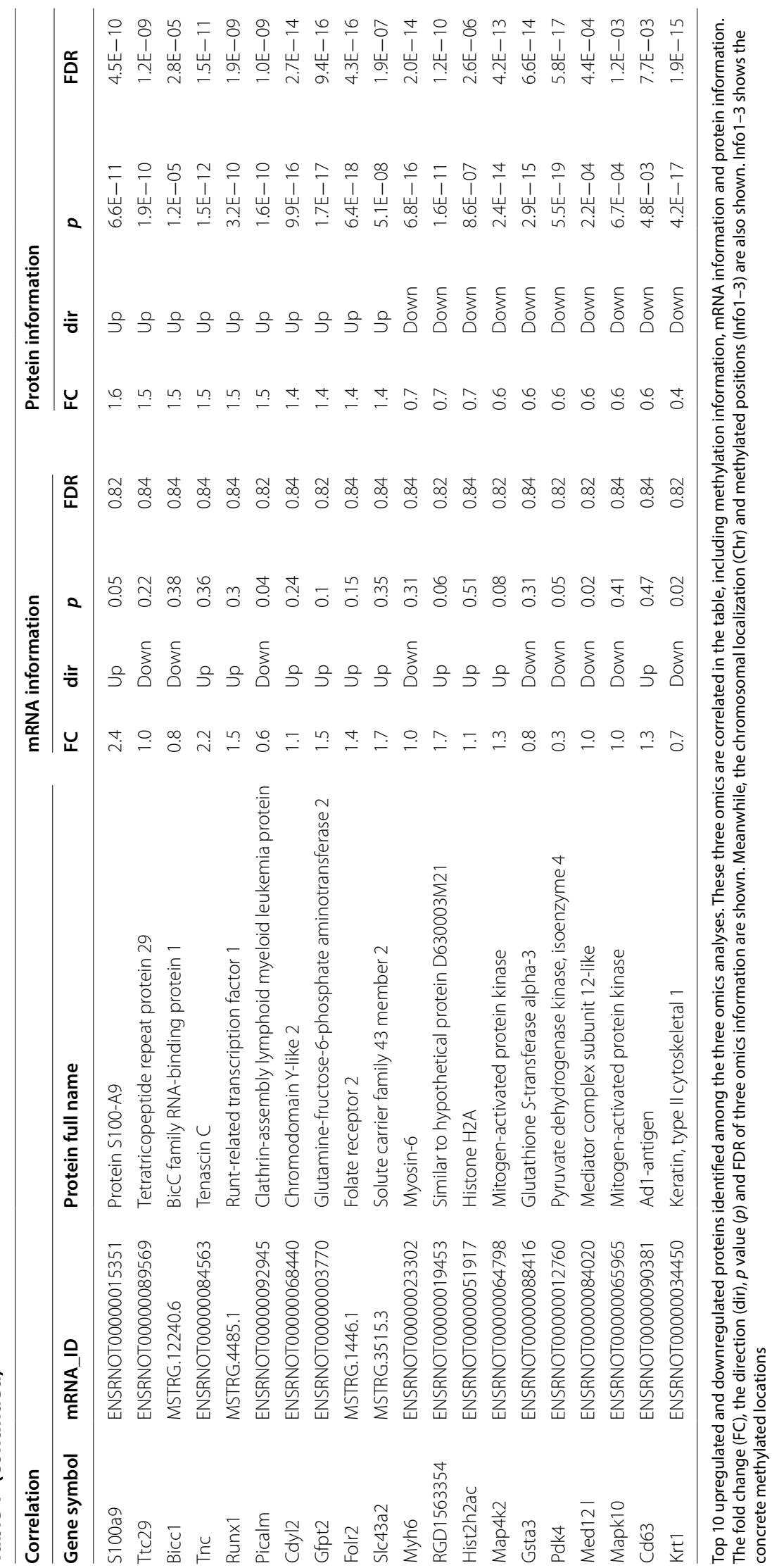




\section{a}

Human Diseases

Systemic lupus erythematosus

Amoebiasis

Leishmaniasis

Pertussis

Environmental Information Processing

ECM-receptor interaction

CGMP-PKG signaling pathway

\section{Cellular Processes
Focal adhesion}

Phagosome

Metabolism

Drug metabolism - cytochrome P450

Metabolism of xenobioti
Glutathione metabolism

Glutathione metabolism

Glycolysis / Gluconeogenesis

Glycolysis / Gluconeogenesis

Arginine and proline metabolism

Organismal Systems

Complement and coagulation cascades

Platelet activation

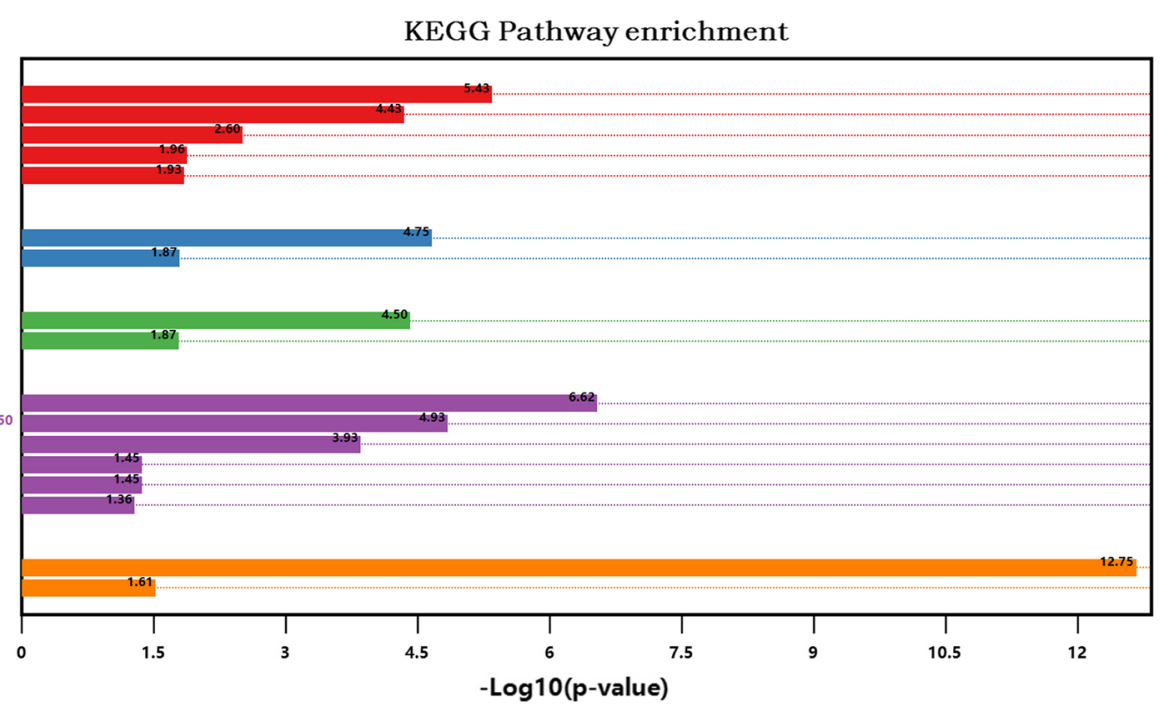

b

biological_process

GO:0045087 innate immune response

(an

60:0006958 complement activation, classical pathway

GO:0098869 cellular oxidant detoxification

G0:0010951 negative regulation of endopeptidase activity

60:0006749 qlutathione metabolic process

60:0042178 xenobiotic catabolic process

60:0070458 cellular detoxification of nitrogen

60:0007596 blood coagulation

0.0007596 mlood coaglation

G0:0072378 brotod coagulation, fibrin clot formation

60:0034116 positive regulation of heterotypic cell-cell adhesion

GO:0007160 cell-matrix adhesion

GO:0042554 - superoxide anion generation

60:0050665 hydrogen peroxide biosynthetic process

GO:0006801 - superoxide metabolic process

60:0006911 phagocytosis, engulfment

60:0006910 - phagocytosis, recognitio

(0.0010880 regulation of release of sequestered calcium ion in

0:0046314 phosphocreatine biosynthetic process

60:0009115 xanthine catabolic process

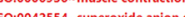

0000674 ealutar alcion ion hotion

cellular_component

GO:0016529 sarcoplasmic reticulum

60:0005578 proteinaceous extracellular matrix

GO:0005581 collagen trimer

60:0005577 fibrinogen complex

60:0001725 stress fiber

60:0005587 collagen type IV trimer

60:0005587 collagen type IV

G0:0016459 myosin

60:0005887-integral component of plasma membrone

molecular_function

60:0016209 antioxidant activity

60:0005201 extracellular matrix structural constituent

Go:0004867 serine-type endopeptidase inhibitor activity

60:0004364 glutathione transferase activity

60:0043295 glutathione binding

.

60:0030674 protein binding, bridging

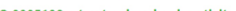

60.0034987

G0:0030247 polysaccharide binding

60:0005201 extracelly ar matrix structural constituent

GO:0004111 creatine kinase activity

GO:0050786 RAGE receptor binding

60:0004854 xanthine dehydrogenase activity

G0:0055056 D-glucose transmembrane transporter activity

G0:0019825 axygen bindin

o:0003823 antigen bindirip

GO enrichment

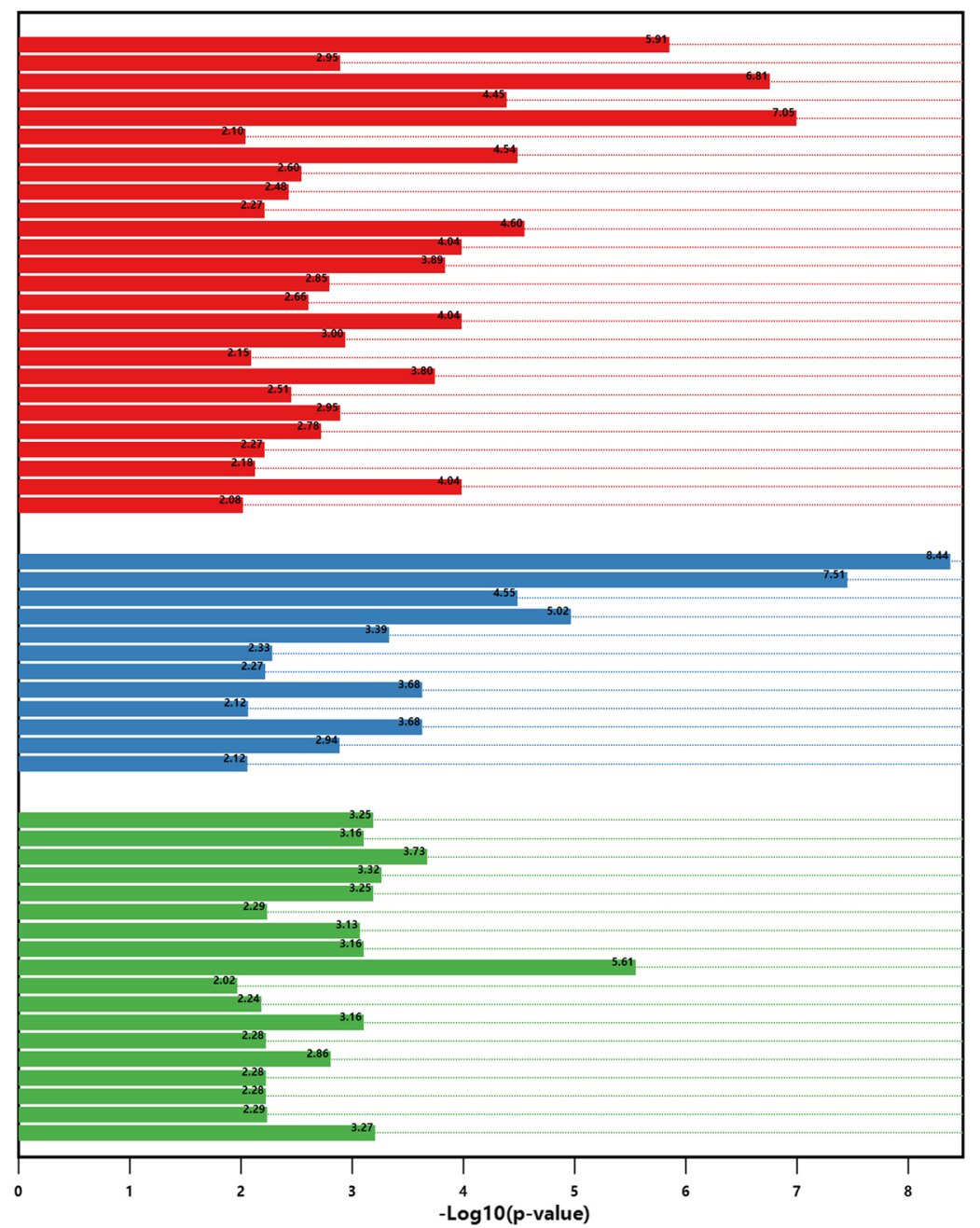

Fig. 3 Functional classifications based on pathway enrichment analysis of differentially expressed proteins in the hypoxic group compared with the control group. a The KEGG pathway classification of DEPs $(p<0.05)$. b GO functional classification of DEPs $(p<0.01)$. $\mathbf{c}$, $\mathbf{d}$ Rich factor of significant KEGG pathways and GO terms 
c

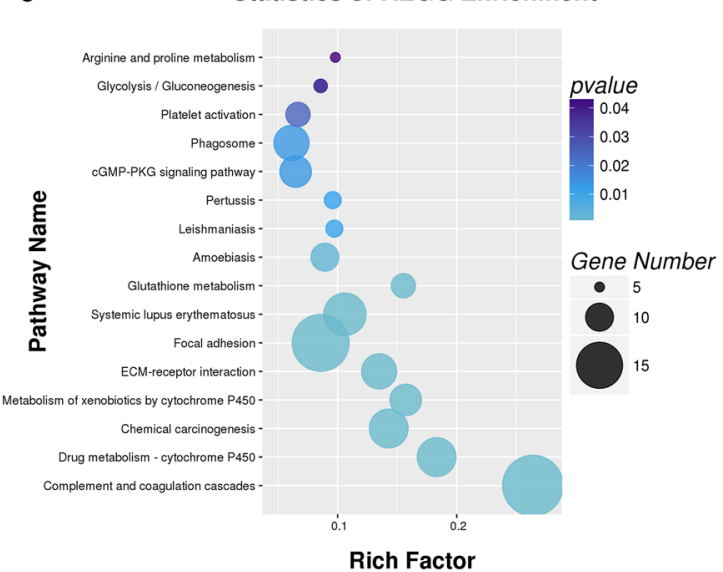

Fig. 3 (continued)

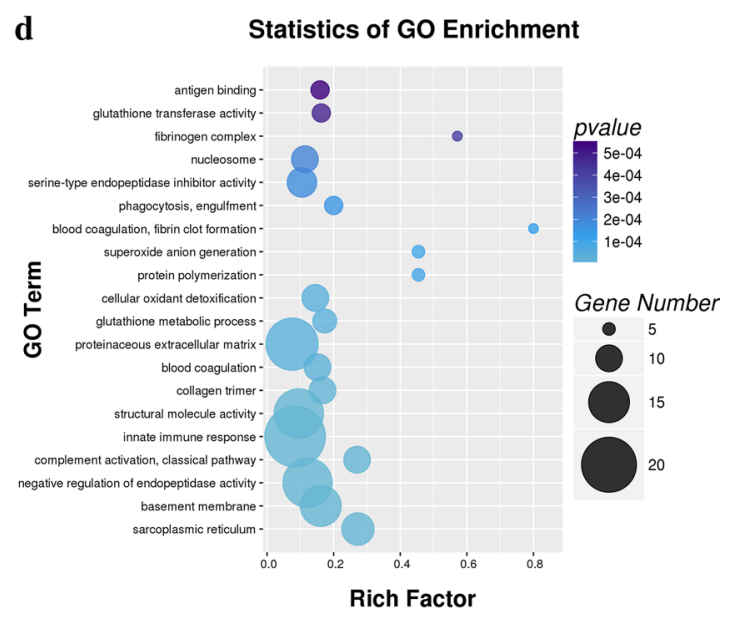

investigate the therapeutic actions and associated mechanisms of osthole in rats with $\mathrm{PAH}$ induced by experimental monocrotaline (MCT). This study reported that the complement and coagulation cascade pathway was significantly disordered in PAH lungs [4]. In our sequencing data, within this pathway, the Kng1 and Thbd genes were the most significantly upregulated and downregulated genes, respectively. Interestingly, the changes in Kng1 and Thbd expression were consistently validated by real-time PCR and Western blotting analyses in our study. According to previous studies, Kng1 can influence the activated partial thromboplastin time and the risk of thrombosis [34] as well as key components of the renin-angiotensin-aldosterone system, which is critical for the regulation of blood pressure and fluid balance and influences cardiovascular remodeling [35]. In this regard, Thbd might slightly delay the progression of MCT-induced PAH [36]. PAs were utilized in compartment-specific gene expression patterns in three previous studies. Some of these results were consistent with our data. Hoffmann et al. reported gene expression data from patients with chronic obstructive pulmonary disease and idiopathic pulmonary fibrosis (IPF) with pulmonary hypertension. They found that the retinol metabolism and ECM receptor interaction were the most perturbed processes [8]. In our results, the $p$-values for these two pathways were 0.043 and $1.79 \mathrm{E}-05$, respectively. In addition, several genes, including Tnc (upregulated), Thbs2 (upregulated) and Vwf (downregulated), were reported to be involved in ECM receptor interaction, in agreement with our data. Laumanns et al. [11] performed transcriptome-wide expression profiling of laser microdissected PA resistance vessels derived from explanted idiopathic $\mathrm{PAH}$ and nontransplanted donor lung tissues. Consistent with our data, the focal adhesion and ECM-receptor interaction pathways were found to be significant pathways. In our results, the top regulated genes from the focal adhesion and ECM-receptor interaction pathways were Col4a 1 and Col2a1. In addition, Itga 5 was identified as hub node for the PPI networks of these two pathways. Functionally, Col2a1 has been reported to be involved in the arterial tortuosity syndrome, which is often associated with PA stenosis and pulmonary hypertension [37]. Col4a1 was associated with several vascular defects, including arterial stiffness and myocardial infarction [38, 39]. Similarly, Itga5 has been shown to enhance cell adhesion, cell viability, cell migration and nitric oxide production [40]. Patel et al. [10] compared pulmonary arteriole gene expression from 16 IPF patients, including eight with PAH (PAH-IPF) and eight without PAH (NPAHIPF), and seven controls. They found that the expression levels of Stat1 and Smoc2, a transcription factor and an extracellular protein, respectively, associated with vascular proliferation, were increased in IPF arteriole, which was validated with immunohistochemical staining. Meanwhile, in our data, STAT1 and SMOC2 were significantly upregulated at both the mRNA and protein levels. The above three studies of PAs were conducted on human

(See figure on next page.)

Fig. 4 The multiomics information of the selected KEGG pathways. The means of the gene and protein expression levels from the hypoxic and control groups were compared. The data $\geq 0$ in the heatmap (slant yellow and red) were upregulated, whereas data $<0$ in the heatmap (partial red) were downregulated. Meanwhile, the methylation information, including methylation position, positive or negative chain, and the regulation of methylation are shown to the right of each graph. a-e represent complement and coagulation cascades, drug metabolism-cytochrome P450, metabolism of xenobiotics by cytochrome P450, ECM-receptor interaction and focal adhesion, respectively 


\section{a Complement and coagulation cascades}

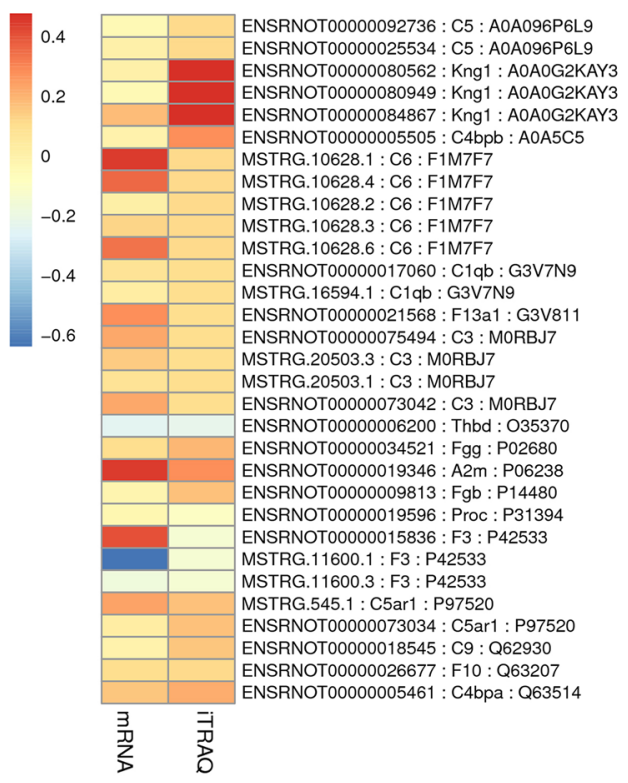

c Metabolism of xenobiotics by cytochrome P450

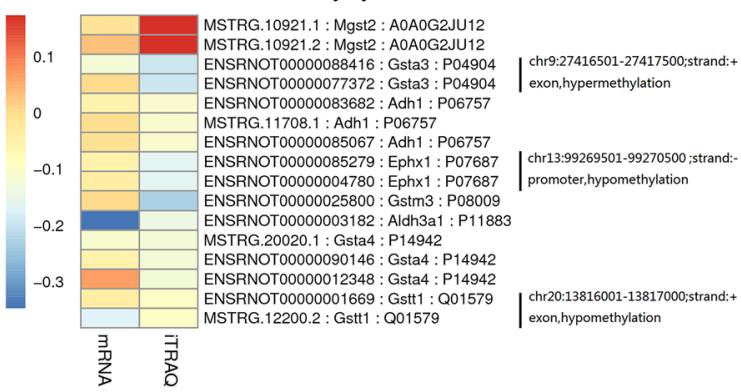

\section{d ECM-receptor interaction}

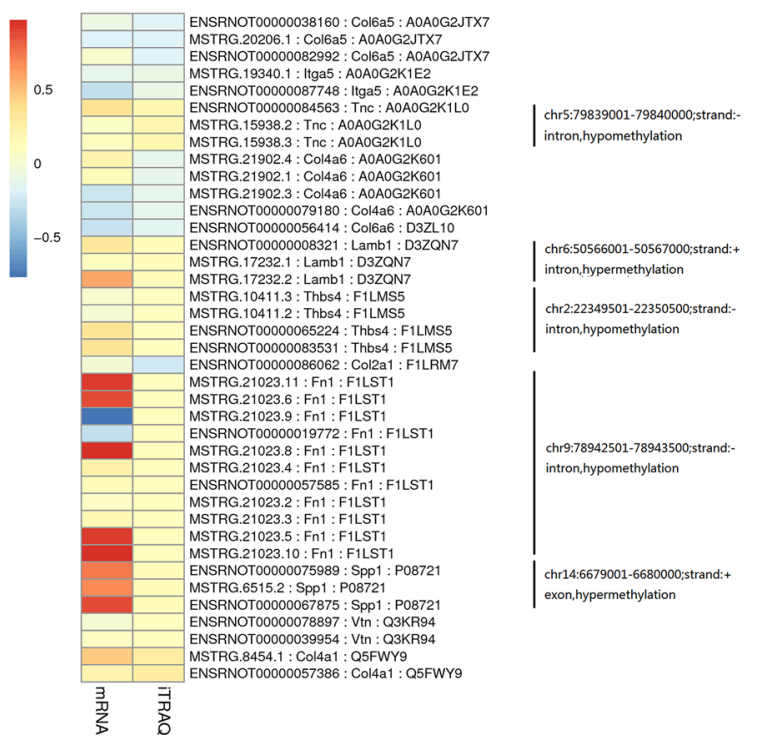

\section{b Drug metabolism-cytochrome P450}

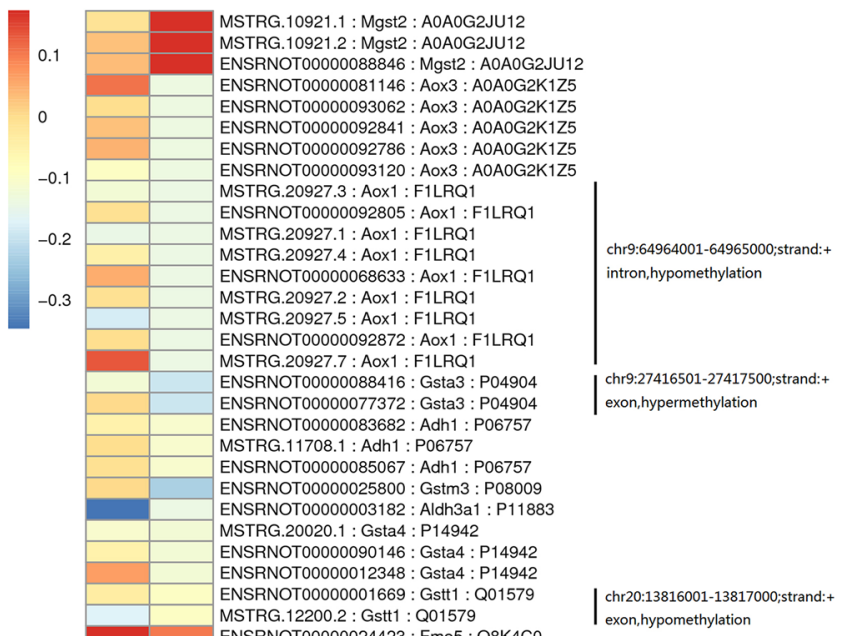

\section{e Focal adhesion}

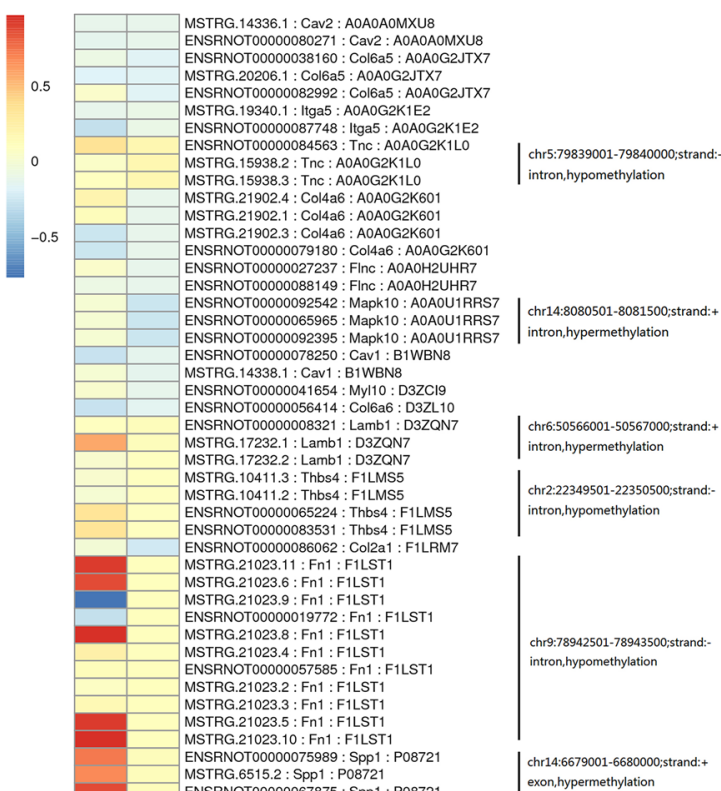




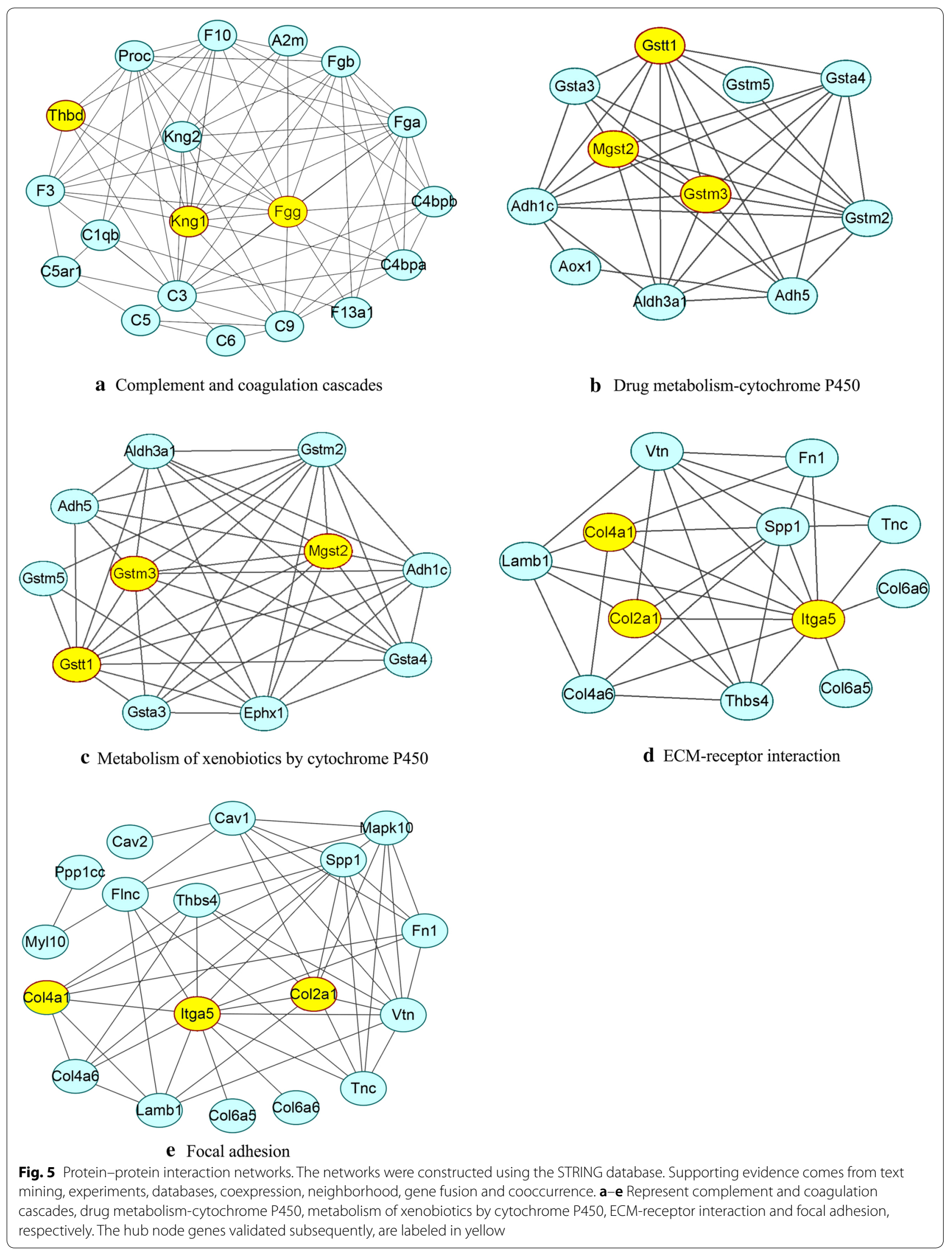


Table 2 The degrees of gene and the expression fold change of proteins in each significant KEGG pathway (pathway enriched FDR < 0.05)

\begin{tabular}{|c|c|c|c|c|}
\hline KEGG-pathway & Gene symbol & Name & Degree & $\mathrm{FC}$ \\
\hline \multirow[t]{12}{*}{ ECM-receptor interaction } & $\operatorname{ltg} a 5$ & Integrin subunit alpha 5 & 11 & 0.79 \\
\hline & Spp1 & Secreted phosphoprotein 1 & 8 & 1.32 \\
\hline & $V \operatorname{tn}$ & Vitronectin & 7 & 1.28 \\
\hline & Thbs4 & Thrombospondin 4 & 6 & 1.26 \\
\hline & Col4ar & Collagen, type IV, alpha 1 & 6 & 1.88 \\
\hline & Lamb1 & Laminin, beta 1 & 5 & 1.31 \\
\hline & Col4a6 & Collagen, type IV, alpha 6 & 5 & 0.78 \\
\hline & Col2ar & Collagen, type Il, alpha 1 & 5 & 0.58 \\
\hline & $\mathrm{Fn} 1$ & Fibronectin 1 & 4 & 1.27 \\
\hline & Tnc & Tenascin C & 3 & 1.49 \\
\hline & Col6a6 & Collagen, type VI, alpha 6 & 1 & 0.72 \\
\hline & Col6a5 & Collagen, type VI, alpha 5 & 1 & 0.69 \\
\hline \multirow[t]{18}{*}{ Focal adhesion } & $\operatorname{ltg} a 5$ & Integrin subunit alpha 5 & 12 & 0.79 \\
\hline & Spp1 & Secreted phosphoprotein 1 & 10 & 1.32 \\
\hline & $V \operatorname{tn}$ & Vitronectin & 9 & 1.28 \\
\hline & Cav1 & Caveolin 1 & 7 & 0.73 \\
\hline & Mapk10 & Mitogen activated protein kinase 10 & 7 & 0.63 \\
\hline & Col2ar & Collagen, type II, alpha 1 & 6 & 0.58 \\
\hline & Col4ar & Collagen, type IV, alpha 1 & 6 & 1.88 \\
\hline & Flnc & Filamin C, gamma & 6 & 0.75 \\
\hline & Fn1 & Fibronectin 1 & 6 & 1.27 \\
\hline & Lamb1 & Laminin, beta 1 & 6 & 1.31 \\
\hline & Thbs4 & Thrombospondin 4 & 6 & 1.26 \\
\hline & Tnc & Tenascin C & 6 & 1.49 \\
\hline & Col4a6 & Collagen, type IV, alpha 6 & 5 & 0.78 \\
\hline & Myl10 & Myosin, light chain 10 , regulatory & 2 & 0.77 \\
\hline & Cav2 & Caveolin 2 & 1 & 0.76 \\
\hline & Col6a5 & Collagen, type VI, alpha 5 & 1 & 0.69 \\
\hline & Col6a6 & Collagen, type VI, alpha 6 & 1 & 0.72 \\
\hline & Ppp1cc & Protein phosphatase 1 catalytic subunit gamma & 1 & 0.72 \\
\hline \multirow[t]{13}{*}{ Drug metabolism-cytochrome P450 } & Gstm2 & Glutathione S-transferase mu 2 & 9 & 0.73 \\
\hline & Gstt1 & Glutathione S-transferase theta 1 & 9 & 0.80 \\
\hline & Adh1c & Alcohol dehydrogenase 1C (class I) & 8 & 0.78 \\
\hline & Gstm3 & Glutathione S-transferase mu 3 & 8 & 0.59 \\
\hline & Mgst2 & Microsomal glutathione S-transferase 2 & 8 & 1.50 \\
\hline & Adh5 & Alcohol dehydrogenase 5 (class III) & 7 & 0.78 \\
\hline & Aldh3a1 & Aldehyde dehydrogenase 3 family, member A1 & 7 & 0.72 \\
\hline & Aox3 & Aldehyde oxidase 3 & 0 & 0.73 \\
\hline & Gsta4 & Glutathione S-transferase alpha 4 & 7 & 0.76 \\
\hline & Gsta3 & Glutathione S-transferase alpha 3 & 5 & 0.64 \\
\hline & Aox1 & Aldehyde oxidase 1 & 2 & 0.73 \\
\hline & Gstm5 & Glutathione S-transferase, mu 5 & 2 & 0.67 \\
\hline & Fmo5 & Flavin containing monooxygenase 5 & 0 & 1.27 \\
\hline
\end{tabular}


Table 2 (continued)

\begin{tabular}{|c|c|c|c|c|}
\hline KEGG-pathway & Gene symbol & Name & Degree & FC \\
\hline \multirow[t]{11}{*}{ Metabolism of xenobiotics by cytochrome P450 } & Gstm2 & Glutathione S-transferase mu 2 & 10 & 0.73 \\
\hline & Gstt1 & Glutathione S-transferase theta 1 & 10 & 0.80 \\
\hline & Ephx1 & Epoxide hydrolase 1 & 9 & 0.69 \\
\hline & Gstm3 & Glutathione S-transferase mu 3 & 9 & 0.59 \\
\hline & Mgst2 & Microsomal glutathione S-transferase 2 & 9 & 1.50 \\
\hline & Adh1c & Alcohol dehydrogenase 1C (class I) & 8 & 0.78 \\
\hline & Aldh3a1 & Aldehyde dehydrogenase 3 family, member A1 & 8 & 0.72 \\
\hline & Gsta4 & Glutathione S-transferase alpha 4 & 8 & 0.76 \\
\hline & Adh5 & Alcohol dehydrogenase 5 (class III) & 6 & 0.78 \\
\hline & Gsta3 & Glutathione S-transferase alpha 3 & 6 & 0.64 \\
\hline & Gstm5 & Glutathione S-transferase, mu 5 & 3 & 0.67 \\
\hline \multirow[t]{20}{*}{ Complement and coagulation cascades } & C3 & Complement C3 & 16 & 1.26 \\
\hline & Fgg & Fibrinogen gamma chain & 14 & 1.57 \\
\hline & Fga & Fibrinogen alpha chain & 12 & 1.60 \\
\hline & Kngl & Kininogen 1 & 12 & 3.01 \\
\hline & F10 & Coagulation factor $X$ & 11 & 1.32 \\
\hline & $\mathrm{Fgb}$ & Fibrinogen beta chain & 10 & 1.49 \\
\hline & Kng2 & Kininogen 2 & 10 & 1.80 \\
\hline & Proc & Protein C & 10 & 0.79 \\
\hline & C9 & Complement component 9 & 9 & 1.44 \\
\hline & F3 & Coagulation factor III & 9 & 0.71 \\
\hline & C4bpa & Complement component 4 binding protein, alpha & 7 & 1.64 \\
\hline & C4bpb & Complement component 4 binding protein, beta & 7 & 1.90 \\
\hline & Thbd & Thrombomodulin & 6 & 0.62 \\
\hline & $\mathrm{C} 1 \mathrm{qb}$ & Complement C1q B chain & 5 & 1.25 \\
\hline & C5 & Complement component 5 & 4 & 1.29 \\
\hline & C5ar1 & Complement C5a receptor 1 & 4 & 1.47 \\
\hline & F13a1 & Coagulation factor XIII A1 chain & 4 & 1.27 \\
\hline & $\mathrm{A} 2 \mathrm{~m}$ & Alpha-2-macroglobulin & 3 & 1.93 \\
\hline & C6 & Complement component 6 & 3 & 1.31 \\
\hline & Kng2l1 & Kininogen 2-like 1 & 0 & 1.55 \\
\hline
\end{tabular}

The KEGG pathway name, gene symbol, gene name, the degree of gene in the PPI network and the FC of proteins are shown. These genes validated subsequently, are highlighted in italic

beings. Interestingly, there was a great deal of consistency between their results and ours. Therefore, our results are more persuasive and have a certain clinical significance. Two other significantly regulated pathways were drug metabolism-cytochrome P450 and metabolism of xenobiotics by cytochrome P450. Xet et al. indicated that the activation of the drug metabolism-cytochrome P450 pathway in cardiomyocytes through derived endothelial cell crosstalk could be crucial for cardioprotection under oxidative stress conditions [41]. Cytochrome P450 has been shown to be prevalent in inflammation-related disorders, including cardiovascular disease [42]. Overall, these results indicate that the genes related to our selected pathways might play important roles in the formation processes involved in hypoxia-induced PAH.
Genes in the selected KEGG pathways contained methylation information, included Tnc, Fn1, Lamb1, Thbs4, Spp1, Mapk10, Aox1, Gsta3, Gstt1 and Ephx1. The methylated genes were associated with proliferation or apoptosis and the regulation of a range of cardiovascular diseases. Tnc promotes glioblastoma invasion and negatively regulates tumor proliferation [43]. Meanwhile, Tnc has been associated with worse left ventricular remodeling and long-term outcomes in dilated cardiomyopathy cases [44]. Wang et al. [45] demonstrated an essential role for the localized synthesis of Fn1 during cardiovascular development and the spatial regulation of Notch signaling. Overall, these methylated genes were generally indirectly correlated with the development of $\mathrm{PAH}$, and there have been few 

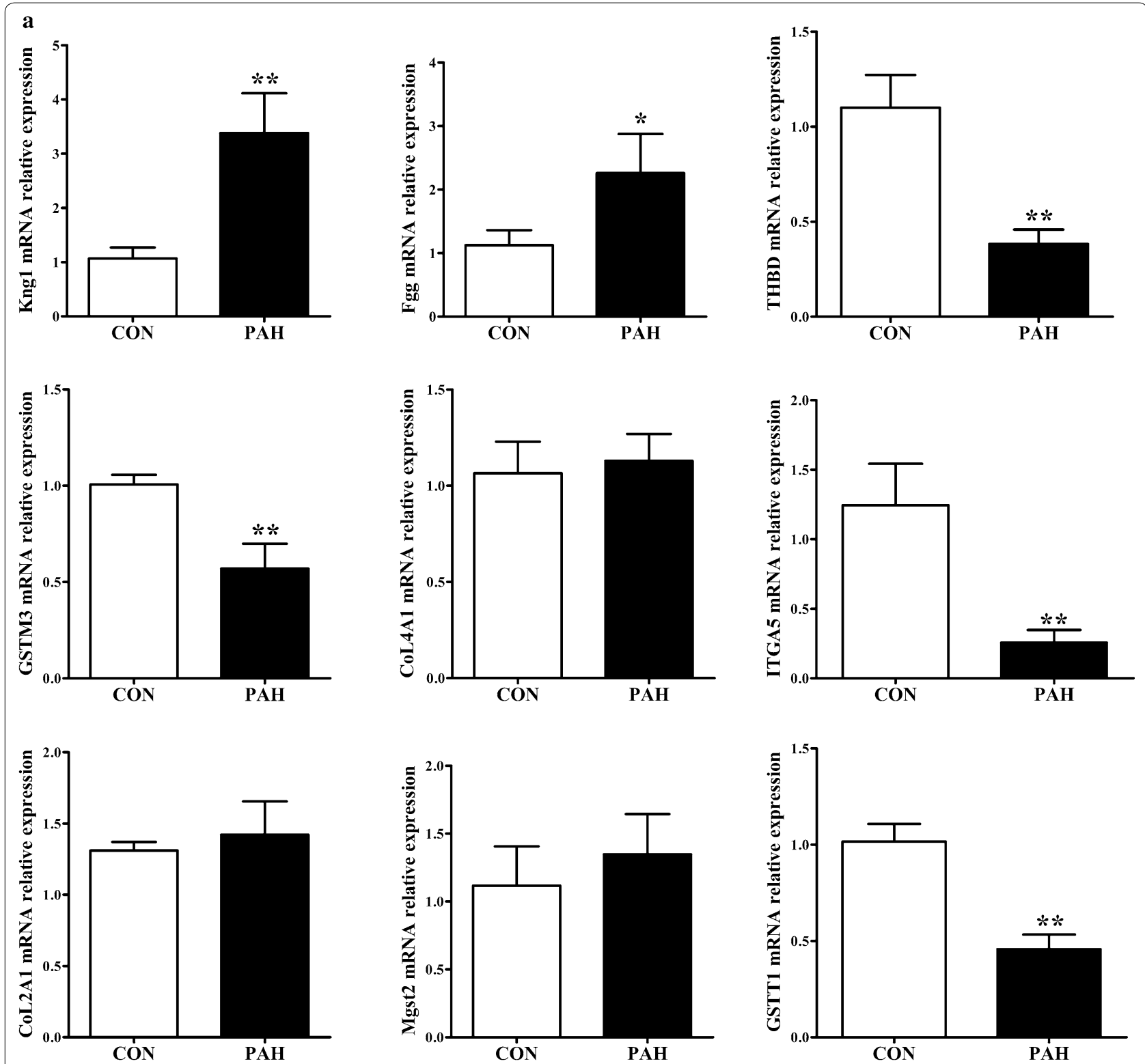

Fig. 6 Validation of candidate gene expression with real-time PCR and Western blot analyses. Data were normalized to $\beta$-actin and are presented as means with confidence intervals, ${ }^{*} p<0.05,{ }^{* *} p<0.01$. a The relative mRNA expression levels of Col2a1, Col4a1, Fgg, Gstm3, Gstt1, Itga5, Kng 1, Mgst2 and Thbd. $\mathbf{b}$ Validation of the protein expression levels with Western blot analysis

studies on these genes during PAH. Epigenetic factors also play important roles in the formation and development of $\mathrm{PAH}$, and these methylated genes may serve as guides for further research into the pathogenesis of PAH.

One limitation of this study is that the experiments were performed only at the animal level. These results have not been validated by the examination of PAs from human case samples. However, previous studies on human samples have shown a great deal of consistency with our results, confirming our results and demonstrating that our data have clinical significance. An integrated analysis of mRNA and protein levels can provide more comprehensive information to better understand gene regulation [46]. Moreover, we integrated methylation information to achieve a more profound understanding of hypoxia-induced $\mathrm{PAH}$ and to reveal the pathogenic mechanisms of PAH. In the future, the use of omics and systems biology approaches should be extended to fully identify the more detailed pathogenic 

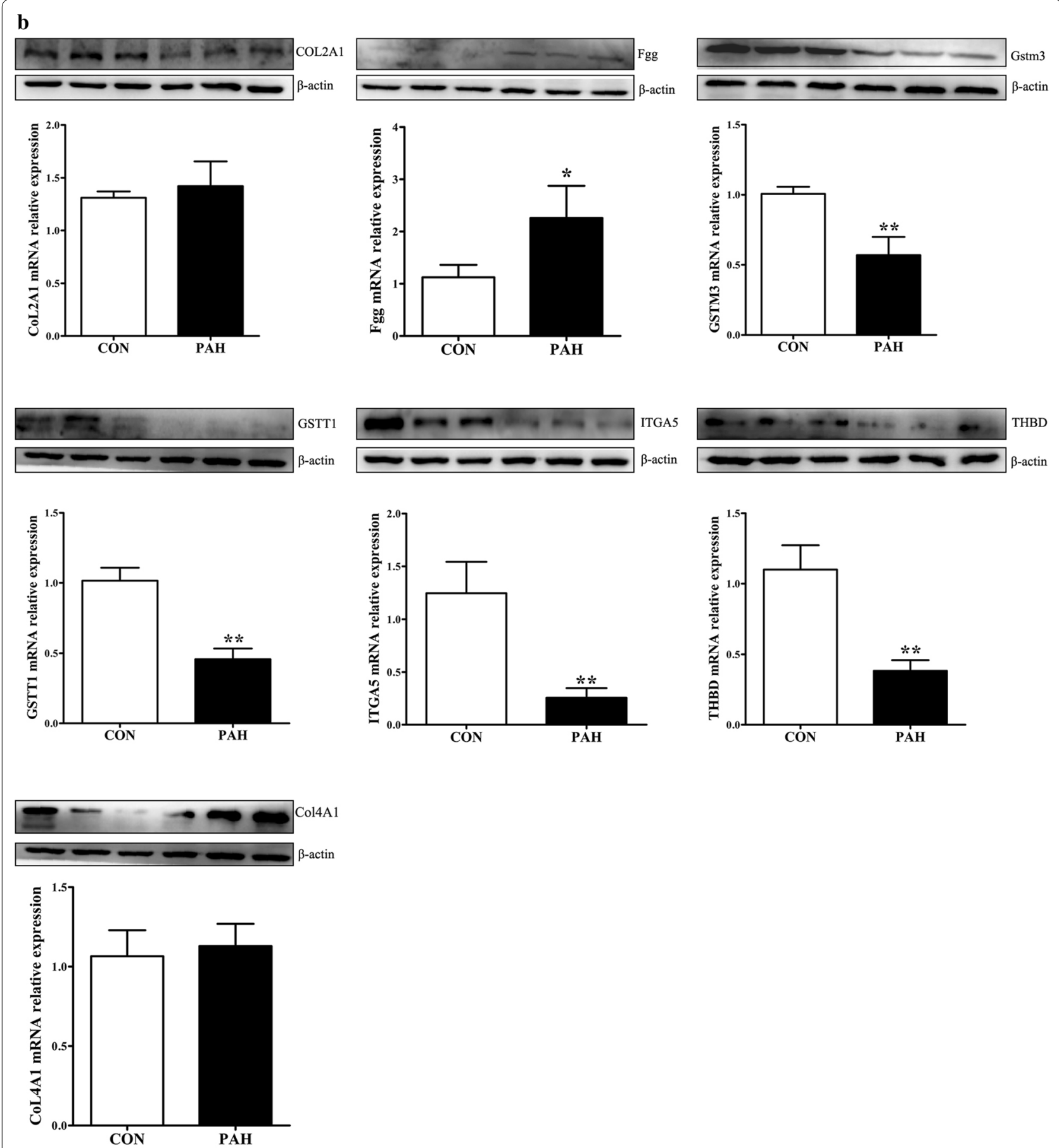

Fig. 6 (continued)

mechanisms of key genes and pathways. Another limitation of this study is that sex differences were not considered. The basic blood pressure of male and female rats is different, as is the incidence of disease. In this study, we used male rats to establish PAH models which were agreed with previous publications [47-49].

\section{Conclusions}

In summary, we have identified key genes and potential pathways associated with the development of PAH through pathway enrichment and PPI analyses, which may play important roles during pulmonary vascular remodeling and pulmonary hypertension. Our findings 
provide a general overview that integrates the dysfunctional characteristics associated with PAH as determined by three omics analyses. This study has contributed to the understanding of the injury mechanisms underlying $\mathrm{PAH}$ and to the possible development of new drugs and therapeutic targets for PAH.

\section{Additional files}

Additional file 1: Table S1. The table summary of RNA-seq quality control
data.

Additional file 2: Table S2. Integrated analysis of three omics characteristics.

Additional file 3: Table S3. GO enrichment analysis ( $p$-value <0.05).

Additional file 4: Table S4. The detailed information of the significant KEGG pathways.

\section{Abbreviations}

PAH: pulmonary artery hypertension; mPAP: mean pulmonary artery pressure; PAs: pulmonary arteries; SD: Sprague-Dawley; RNA-seq: RNA sequencing; TMT: tandem mass tags; RRBS: reduced representation bisulfite sequencing; DEGs: differentially expressed genes; DEPs: differentially expressed proteins; DMRs: differentially methylated regions; RVSP: right ventricle systolic pressure; RVMI: right ventricular mass index; HPLC: high performance liquid chromatography; MS/MS: tandem mass spectrometry; LC: liquid chromatography; MS: mass spectrometry; AGC: automatic gain control; FDR: false discovery rate; GO: Gene Ontology; KEGG: Kyoto Encyclopedia of Genes and Genomes; PPI: protein-protein interaction; STRING: Search Tool for the Retrieval of Interacting Genes; MCT: monocrotaline; IPF: idiopathic pulmonary fibrosis.

\section{Acknowledgements}

This work was supported by the National Natural Science Foundation of China (81300036, 31600956, and 31571179), the Natural Science Foundation of Fujian Province, China (Grant No. 2018J01828 and No. 2018J06021), Young and Middle-aged Backbone Personnel Training Project of Fujian Health and Family Planning Commission (2018-ZQN-59) and Fujian Medical University Talent Startup Fund (XRCZX2017003 and XRCZX2017004). We would like to thank the anonymous reviewers for their valuable comments and suggestions, which helped improve the quality of our manuscript.

\section{Authors' contributions}

LZ, SKC and MJL conceived and designed the overall study. XXZ, DCL and LXG generated the PAH rat models. SKC conducted the bioinformatics analysis. $L Z$, SKC, XXZ, DCL and LXG performed Western blot and real-time PCR analyses; $L Z, S K C, Y M L$ and MJL analyzed data for the key genes and proteins screening and wrote the manuscript. All authors read and approved the final manuscript.

\section{Funding}

The National Natural Science Foundation of China (81300036, 31600956, and 31571179), The Natural Science Foundation of Fujian Province, China (Grant No. 2018J01828 and No. 2018J06021), Young and Middle-aged Backbone Personnel Training Project of Fujian Health and Family Planning Commission (2018-ZQN-59) and Fujian Medical University Talent Startup Fund (XRCZX2017003 and XRCZX2017004).

\section{Availability of data and materials}

The data generated or analyzed during this study are available from the corresponding author upon reasonable request.

\section{Ethics approval and consent to participate}

This study was approved by the institutional review boards of all participating institutions, and written consent forms were obtained from all participants.

\section{Consent for publication}

All of the authors listed for this paper consent to the publication of this work.

\section{Competing interests}

The authors declare that they have no competing interests.

\section{Author details}

${ }^{1}$ Department of Physiology \& Pathophysiology, Fujian Medical University, Fuzhou, China. ${ }^{2}$ The Key Laboratory of Fujian Province University on Ion Channel and Signal Transduction in Cardiovascular Disease, School of Basic Medical Sciences, Fujian Medical University, Fuzhou, China. ${ }^{3}$ Fujian Center for Safety Evaluation of New Drug, Fujian Medical University, Fuzhou, China.

Received: 17 February 2019 Accepted: 12 July 2019

Published online: 22 July 2019

\section{References}

1. Barst RJ, McGoon M, Torbicki A, Sitbon O, Krowka MJ, Olschewski H, Gaine S. Diagnosis and differential assessment of pulmonary arterial hypertension. J Am Coll Cardiol. 2004:43:40S-7S.

2. Frump AL, Albrecht ME, McClintick JN, Lahm T. Estrogen receptordependent attenuation of hypoxia-induced changes in the lung genome of pulmonary hypertension rats. Pulm Circ. 2017;7:232-43.

3. Abdul-Salam VB, Wharton J, Cupitt J, Berryman M, Edwards RJ, Wilkins MR. Proteomic analysis of lung tissues from patients with pulmonary arterial hypertension. Circulation. 2010;122:2058-67.

4. Yao L, Yang Y, He G, Ou C, Wang L, Liu K. Global proteomics deciphered novel-function of osthole against pulmonary arterial hypertension. Sci Rep. 2018:8:5556.

5. Hoffmann J, Yin J, Kukucka M, Yin N, Saarikko I, Sterner-Kock A, Fujii H, Leong-Poi H, Kuppe H, Schermuly RT, Kuebler WM. Mast cells promote lung vascular remodelling in pulmonary hypertension. Eur Respir J. 2011:37:1400-10.

6. Graham BB, Chabon J, Kumar R, Kolosionek E, Gebreab L, Debella E, Edwards M, Diener K, Shade T, Bifeng G, Bandeira A, Butrous G, Jones K, Geraci M, Tuder RM. Protective role of IL-6 in vascular remodeling in Schistosoma pulmonary hypertension. Am J Respir Cell Mol Biol. 2013:49:951-9.

7. Shimodaira K, Okubo Y, Ochiai E, Nakayama H, Katano H, Wakayama M, Shinozaki M, Ishiwatari T, Sasai D, Tochigi N, Nemoto T, Saji T, Kamei K, Shibuya K. Gene expression analysis of a murine model with pulmonary vascular remodeling compared to end-stage IPAH lungs. Respir Res. 2012;13:103.

8. Hoffmann J, Wilhelm J, Marsh LM, Ghanim B, Klepetko W, Kovacs G, Olschewski H, Olschewski A, Kwapiszewska G. Distinct differences in gene expression patterns in pulmonary arteries of patients with chronic obstructive pulmonary disease and idiopathic pulmonary fibrosis with pulmonary hypertension. Am J Respir Crit Care Med. 2014;190:98-111.

9. Wang J, Xu L, Yun X, Yang K, Liao D, Tian L, Jiang H, Lu W. Proteomic analysis reveals that proteasome subunit beta 6 is involved in hypoxia-induced pulmonary vascular remodeling in rats. PLoS ONE. 2013;8:e67942.

10. Patel NM, Kawut SM, Jelic S, Arcasoy SM, Lederer DJ, Borczuk AC. Pulmonary arteriole gene expression signature in idiopathic pulmonary fibrosis. Eur Respir J. 2013;41:1324-30.

11. Laumanns IP, Fink L, Wilhelm J, Wolff JC, Mitnacht-Kraus R, Graef-Hoechst S, Stein MM, Bohle RM, Klepetko W, Hoda MA, Schermuly RT, Grimminger F, Seeger W, Voswinckel R. The noncanonical WNT pathway is operative in idiopathic pulmonary arterial hypertension. Am J Respir Cell Mol Biol. 2009:40:683-91.

12. Li M, Vattulainen S, Aho J, Orcholski M, Rojas V, Yuan K, Helenius M, Taimen P, Myllykangas S, De Jesus Perez V, Koskenvuo JW, Alastalo TP. Loss of bone morphogenetic protein receptor 2 is associated with abnormal DNA repair in pulmonary arterial hypertension. Am J Respir Cell Mol Biol. 2014;50:1118-28.

13. Rhodes CJ, Im H, Cao A, Hennigs JK, Wang L, Sa S, Chen PI, Nickel NP, Miyagawa K, Hopper RK, Tojais NF, Li CG, Gu M, Spiekerkoetter E, Xian Z, Chen R, Zhao M, Kaschwich M, Del Rosario PA, Bernstein D, Zamanian RT, Wu JC, Snyder MP, Rabinovitch M. RNA sequencing analysis detection of a novel pathway of endothelial dysfunction in pulmonary arterial hypertension. Am J Respir Crit Care Med. 2015;192:356-66. 
14. Cheong FY, Gower AC, Farber HW. Changes in gene expression profiles in patients with pulmonary arterial hypertension associated with scleroderma treated with tadalafil. Semin Arthritis Rheum. 2017;46:465-72.

15. Chesne J, Danger R, Botturi K, Reynaud-Gaubert M, Mussot S, Stern M, Danner-Boucher I, Mornex JF, Pison C, Dromer C, Kessler R, Dahan M, Brugiere O, Le Pavec J, Perros F, Humbert M, Gomez C, Brouard S, Magnan A, Consortium C. Systematic analysis of blood cell transcriptome in end-stage chronic respiratory diseases. PLoS ONE. 2014;9:e109291.

16. Kim JD, Lee A, Choi J, Park Y, Kang H, Chang W, Lee MS, Kim J. Epigenetic modulation as a therapeutic approach for pulmonary arterial hypertension. Exp Mol Med. 2015;47:e175.

17. Pousada G, Baloira A, Valverde D. Methylation analysis of the BMPR2 gene promoter region in patients with pulmonary arterial hypertension. Arch Bronconeumol. 2016;52:293-8.

18. Saco TV, Parthasarathy PT, Cho Y, Lockey RF, Kolliputi N. Role of epigenetics in pulmonary hypertension. Am J Physiol Cell Physiol. 2014;306:C1101-5.

19. Stenmark KR, Fagan KA, Frid MG. Hypoxia-induced pulmonary vascular remodeling: cellular and molecular mechanisms. Circ Res. 2006;99:675-91.

20. Seeger W, Adir Y, Barbera JA, Champion H, Coghlan JG, Cottin V, De Marco T, Galie N, Ghio S, Gibbs S, Martinez FJ, Semigran MJ, Simonneau G, Wells AU, Vachiery JL. Pulmonary hypertension in chronic lung diseases. J Am Coll Cardiol. 2013;62:D109-16.

21. Bartsch P, Gibbs JS. Effect of altitude on the heart and the lungs. Circulation. 2007;116:2191-202.

22. Kwapiszewska G, Wilhelm J, Wolff S, Laumanns I, Koenig IR, Ziegler A, Seeger W, Bohle RM, Weissmann N, Fink L. Expression profiling of laser-microdissected intrapulmonary arteries in hypoxia-induced pulmonary hypertension. Respir Res. 2005;6:109.

23. Lin MJ, Leung GP, Zhang WM, Yang XR, Yip KP, Tse CM, Sham JS. Chronic hypoxia-induced upregulation of store-operated and receptor-operated $\mathrm{Ca}^{2+}$ channels in pulmonary arterial smooth muscle cells: a novel mechanism of hypoxic pulmonary hypertension. Circ Res. 2004;95:496-505.

24. Liu XR, Liu Q, Chen GY, Hu Y, Sham JS, Lin MJ. Down-regulation of TRPM8 in pulmonary arteries of pulmonary hypertensive rats. Cell Physiol Biochem. 2013:31:892-904

25. Didion JP, Martin M, Collins FS. Atropos: specific, sensitive, and speedy trimming of sequencing reads. PeerJ. 2017:5:e3720.

26. Pertea M, Pertea GM, Antonescu CM, Chang TC, Mendell JT, Salzberg SL. StringTie enables improved reconstruction of a transcriptome from RNAseq reads. Nat Biotechnol. 2015;33:290-5.

27. Frazee AC, Pertea G, Jaffe AE, Langmead B, Salzberg SL, Leek JT. Ballgown bridges the gap between transcriptome assembly and expression analysis. Nat Biotechnol. 2015;33:243-6.

28. Benjamini Y, Drai D, Elmer G, Kafkafi N, Golani I. Controlling the false discovery rate in behavior genetics research. Behav Brain Res. 2001;125:279-84.

29. Chen H, Smith AD, Chen T. WALT: fast and accurate read mapping for bisulfite sequencing. Bioinformatics. 2016;32:3507-9.

30. Li H, Handsaker B, Wysoker A, Fennell T, Ruan J, Homer N, Marth G, Abecasis G, Durbin R, Genome Project Data Processing S. The sequence alignment/ map format and SAMtools. Bioinformatics. 2009;25:2078-9.

31. Song Q, Decato B, Hong EE, Zhou M, Fang F, Qu J, Garvin T, Kessler M, Zhou J, Smith AD. A reference methylome database and analysis pipeline to facilitate integrative and comparative epigenomics. PLOS ONE. 2013:8:e81148.

32. Akalin A, Kormaksson M, Li S, Garrett-Bakelman FE, Figueroa ME, Melnick A, Mason CE. methylKit: a comprehensive R package for the analysis of genome-wide DNA methylation profiles. Genome Biol. 2012;13:R87.

33. Khalyfa A, Gharib SA, Kim J, Dayyat E, Snow AB, Bhattacharjee R, Kheirandish-Gozal L, Goldman JL, Gozal D. Transcriptomic analysis identifies phosphatases as novel targets for adenotonsillar hypertrophy of pediatric obstructive sleep apnea. Am J Respir Crit Care Med. 2010;181:1114-20.

34. Sabater-Lleal M, Martinez-Perez A, Buil A, Folkersen L, Souto JC, Bruzelius M, Borrell M, Odeberg J, Silveira A, Eriksson P, Almasy L, Hamsten A, Soria JM. A genome-wide association study identifies KNG1 as a genetic determinant of plasma factor XI Level and activated partial thromboplastin time. Arterioscler Thromb Vasc Biol. 2012;32:2008-16.

35. Lieb W, Chen MH, Teumer A, de Boer RA, Lin H, Fox ER, Musani SK, Wilson JG, Wang TJ, Volzke H, Petersen AK, Meisinger C, Nauck M, Schlesinger S, Li Y, Menard J, Hercberg S, Wichmann HE, Volker U, Rawal R, Bidlingmaier M,
Hannemann A, Dorr M, Rettig R, van Gilst WH, van Veldhuisen DJ, Bakker SJ, Navis G, Wallaschofski H, Meneton P, van der Harst P, Reincke M, Vasan RS, Consortium CK, Icbp, EchoGen C. Genome-wide meta-analyses of plasma renin activity and concentration reveal association with the kininogen 1 and prekallikrein genes. Circ Cardiovasc Genet. 2015;8:131-40.

36. Yamada Y, Maruyama J, Zhang E, Okada A, Yokochi A, Sawada H, Mitani Y, Hayashi T, Suzuki K, Maruyama K. Effect of thrombomodulin on the development of monocrotaline-induced pulmonary hypertension. J Anesth. 2014;28:26-33.

37. Gardella R, Zoppi N, Assanelli D, Muiesan ML, Barlati S, Colombi M. Exclusion of candidate genes in a family with arterial tortuosity syndrome. Am J Med Genet Part A. 2004;126A:221-8.

38. Tarasov KV, Sanna S, Scuteri A, Strait JB, Orru M, Parsa A, Lin PI, Maschio A, Lai S, Piras MG, Masala M, Tanaka T, Post W, O'Connell JR, Schlessinger D, Cao A, Nagaraja R, Mitchell BD, Abecasis GR, Shuldiner AR, Uda M, Lakatta EG, Najjar SS. COL $4 A 1$ is associated with arterial stiffness by genome-wide association scan. Circ Cardiovasc Genet. 2009;2:151-8.

39. Yamada Y, Kato K, Oguri M, Fujimaki T, Yokoi K, Matsuo H, Watanabe S, Metoki N, Yoshida H, Satoh K, Ichihara S, Aoyagi Y, Yasunaga A, Park H, Tanaka M, Nozawa Y. Genetic risk for myocardial infarction determined by polymorphisms of candidate genes in a Japanese population. J Med Genet. 2008:45:216-21.

40. Chen HY, Pan L, Yang HL, Xia P, Yu WC, Tang WQ, Zhang YX, Chen SF, Xue YZ, Wang LX. Integrin alpha5beta1 suppresses rBMSCs anoikis and promotes nitric oxide production. Biomed Pharmacother. 2018;99:1-8.

41. Yue X, Acun A, Zorlutuna P. Transcriptome profiling of 3D co-cultured cardiomyocytes and endothelial cells under oxidative stress using a photocrosslinkable hydrogel system. Acta Biomater. 2017;58:337-48.

42. Shahabi P, Siest G, Meyer UA, Visvikis-Siest S. Human cytochrome P450 epoxygenases: variability in expression and role in inflammation-related disorders. Pharmacol Ther. 2014;144:134-61.

43. Xia S, Lal B, Tung B, Wang S, Goodwin CR, Laterra J. Tumor microenvironment tenascin- $C$ promotes glioblastoma invasion and negatively regulates tumor proliferation. Neuro-oncology. 2016;18:507-17.

44. Yokokawa T, Sugano Y, Nakayama T, Nagai T, Matsuyama TA, Ohta-Ogo K, Ikeda Y, Ishibashi-Ueda H, Nakatani T, Yasuda S, Takeishi Y, Ogawa H, Anzai T. Significance of myocardial tenascin-C expression in left ventricular remodelling and long-term outcome in patients with dilated cardiomyopathy. Eur J Heart Fail. 2016;18:375-85.

45. Wang $X$, Astrof $S$. Neural crest cell-autonomous roles of fibronectin in cardiovascular development. Development. 2016;143:88-100.

46. Schwanhausser B, Busse D, Li N, Dittmar G, Schuchhardt J, Wolf J, Chen W, Selbach M. Global quantification of mammalian gene expression control. Nature. 2011;473:337-42.

47. da Silva Goncalves Bos D, Van Der Bruggen CEE, Kurakula K, Sun XQ, Casali KR, Casali AG, Rol N, Szulcek R, Dos Remedios C, Guignabert C, Tu L, Dorfmuller P, Humbert M, Wijnker PJM, Kuster DWD, van der Velden J, Goumans MJ, Bogaard HJ, Vonk-Noordegraaf A, de Man FS, Handoko ML. Contribution of impaired parasympathetic activity to right ventricular dysfunction and pulmonary vascular remodeling in pulmonary arterial hypertension. Circulation. 2018;137:910-24.

48. Mao M, Zhang M, Ge A, Ge X, Gu R, Zhang C, Fu Y, Gao J, Wang X, Liu Y, Zhu D. Granzyme B deficiency promotes osteoblastic differentiation and calcification of vascular smooth muscle cells in hypoxic pulmonary hypertension. Cell Death Dis. 2018;9:221.

49. Ma C, LiY, Ma J, Liu Y, Li Q, Niu S, Shen Z, Zhang L, Pan Z, Zhu D. Key role of 15-lipoxygenase/15-hydroxyeicosatetraenoic acid in pulmonary vascular remodeling and vascular angiogenesis associated with hypoxic pulmonary hypertension. Hypertension. 2011;58:679-88.

\section{Publisher's Note}

Springer Nature remains neutral with regard to jurisdictional claims in published maps and institutional affiliations. 